\title{
Spatial Scales of Mesoscale Variability in the North Atlantic as Deduced From Geosat Data
}

\author{
P. Y. LE TRAON AND M. C. Rouquet \\ Collecte Localisation Satellites Argos, Toulonse, France
}

\section{Boissier}

Service Hydrographique et Océanographique de la Marine, Groupe de Recharche en Géodesie Spatiale Centre National d'Endess Spatiales. Toulouse. France'

\begin{abstract}
Two years of Geosat data were used to systematically investigate the mesoscale variability and spatial scales of the North Atlantic. We first calculated sea surface height variability and eddy kinetic energy. These compare well with the eddy kinetic energy obtained with surface drifters. Then the spatial scales of mesoscale variability were characterized in $10^{\circ}$ (latitude) $\times 10^{\circ}$ (longitude) areas by their wave number spectra and autocorrelation functions. Comparison with existing in situ data shows good agreement, and it is believed that the total error budget is globally below that of the oceanic signal. The wave number spectra show significant differences as a function of latitude and longitude, and these can be related to different types of forcing (instability of a mean current or fluctuating wind). Seales typically decrease from west to east and south to north. Simple proportionality with respect to the first internal Rossby radii does not apply everywhere.
\end{abstract}

\section{INTRODUCTION}

The study of mesoscale variability is a major component of oceanographic research today, since ocean eddies play an active role in the general ocean circulation and in the distribution of seawater properties. Despite the considerable progress of the last 20 years, our understanding of eddy dynamics remains incomplete. In particular, observations spread over larger areas and longer time spans are required. To that extent, Seasat satellite altimetry was extremely fruitfui, since it produced a global view of the oceans for the first time. In addition, it showed that spatial sampling by the satellite along its ground track (near-instantaneous over several thousand kilometers) was particularly suitable for calculating the mesoscale variability wave number spectra, these being difficult to obtain from conventional in situ measurements [e.g., $F_{l l}, 1983$ ]. However, the short duration of the mission ( 3 months, with only 24 days in a repetitive orbit) did not provide a means of suitably observing the mesoscale signal, which has time scales varying from around 10 days to several months.

The launch of the U.S. Navy's Geosat altimeter in 1985 or, more precisely, the start of its Exact Repeat Mission (ERM) in November 1986 provided a capability for mesoscale observation over a longer period. The satellite has now been on a near-repeat orbit (17.05-clay cycle) for over 2 years, permitting temporal sampling well suited to mesoscale studies. Good spatiotemporal sampling such as this opens up new scope for global studies of the spatial and temporal scales of mesoscale features. It can reveal differences between regions of the ocean and permit an interpretation in terms of, for example, the mechanisms which generate and dissipate eddies. Pioneering work had already been started by Zlotnicki et al. [1989], who calculated the seasonal

Copyright 1990 by the American Geophysical Union.

Paper number $90.5 \mathrm{C}(01061$

$0148-(2227 / 90 / 90 \mathrm{JA}-(01061 \$ 05.00$ mesoscale variability of the global ocean. The data can also be usefully compared with the results generated by modeling and can be used as input to these models [e.g., De Mey and Ménard, 1989].

The purpose of this paper is to make a systematic study of mesoscale variability and its spatial scales in the North Atlantic $\left(20^{\circ}-60^{\circ} \mathrm{N}, 80^{\circ}-10^{\circ} \mathrm{W}\right)$. The method for computing altimeter residuals is described in section 2. Section 3 covers the calculation of altimetric height variability and geostrophic velocity variability, the latter being compared with drifter data. Section 4 describes the results of the wave number spectra calculations and the characterization of spatial scales. These results are discussed and compared with in situ measurements and models in section 5. Section 6 provides the main conclusions.

\section{Calculation of Altimeter Residuals}

We used 2 years of Geosat geophysical data records (GDRs) obtained from the National Oceanic and Atmospheric Administration (NOAA), spanning the period from November 1986 to November 1988, i.e., 44 cycles of 17.05 days. The sea surface height measurements (SSH) were corrected for the following effects (corrections available in the GDRs): electromagnetic bias by adding $2 \%$ of significant wave height $\left(H_{1 / 3}\right)$ to the SSH, ocean tides using the Schwiderski model, terrestrial tides using the Melchior model, ionospheric effects using the Global Positioning System climatic model, and dry and wet tropospheric effects using Fleet Numerical Oceanography Center data [Cheney et al., 1987]. No inverted barometer correction was applied because of the uncertainties of its estimation [see Zlotnicki of al., 1989].

To eliminate spikes still present in the data, an iterative process was implemented. Each sampled point (sampling rate: I $\mathrm{s}(6.8 \mathrm{~km}))$ was compared with the results of a cubic spline interpolation based on the six closest points. If the difference was greater than $5 \mathrm{~cm}$, the point was moved and 


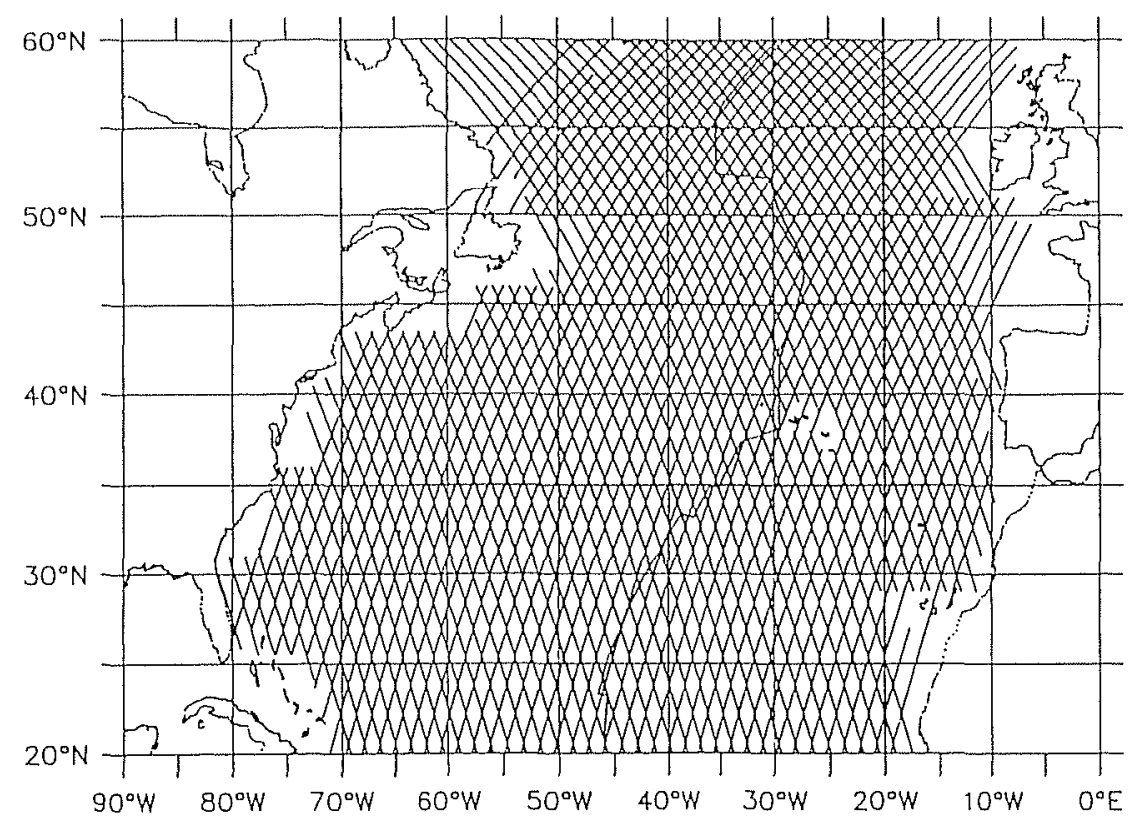

Fig. 1. The study area, in the North Atlantic between $20^{\circ} \mathrm{N}$ and $60^{\circ} \mathrm{N}$; the Geosat tracks used are superimposed. Position of the Mid-Atlantic Ridge is also shown.

corrected according to its interpolated value; the new point was then used for the following iterations. When convergence was achieved, points which had moved more than 30 $\mathrm{cm}$ were flagged while other points kept their initial value. This is an efficient means of eliminating peaks in the data. Around $1 \%$ of the data were rejected by this scheme.

The method developed at the Groupe de Recherche en Géodésie Spatiale (GRGS/Toulouse) is as follows:

1. The area is divided into four $10^{\circ}$-latitude strips between $20^{\circ} \mathrm{N}$ and $60^{\circ} \mathrm{N}$, corresponding to $1500-\mathrm{km}$ arc segments (Figure 1).

2. SSH profiles are resampled every $10 \mathrm{~km}$ using a cubic spline to provide regular sampling. Interpolation is performed only for points surrounded by two valid 1 -s raw data points; for other points, the interpolated point is "missing."

3. Complete profiles are selected, i.e., profiles which have no more than two consecutive missing points over the arc length.

4. A first-degree polynomial is fitted to each individual complete profile, and the mean polynomial is added back to each individual adjusted profile to produce "orbit error free complete profiles."

5. The mean profile is computed as an average of all "orbit error free complete profiles."

6. The mean profile is subtracted from each individual profile (complete or not).

7. A first-degree polynomial adjustment is performed to eliminate long-wavelength components, basically orbit related.

Step 2 provides collocated measurement points for successive passes on each track. Step 3 avoids different geoid contributions to the polynomial adjustment, and step 4 reduces the possible influence of orbit error on the mean profile because of missing points. Step 5 provides our best estimate of the mean sea surface along each track. Steps 6 and 7 give, at the time of the satellite pass on the given track, the mesoscale sea level anomaly (SLA) sampled every 10 $\mathrm{km}$.
The residual data were smoothed before calculating the variability of the altimetric height. The along-track wave number spectrum $E_{1}(k)$ of the unfiltered SLA in Figure $2 a$ obtained from a series of tracks at $30^{\circ}-40^{\circ} \mathrm{N}, 70^{\circ}-60^{\circ} \mathrm{W}$ shows a noise level of around $150 \mathrm{~cm}^{2}$ cycle $^{-1} \mathrm{~km}$ for wavelengths up to around $50-60 \mathrm{~km}$. This white noise corresponds to an rms signal of around $3-4 \mathrm{~cm}$, which must

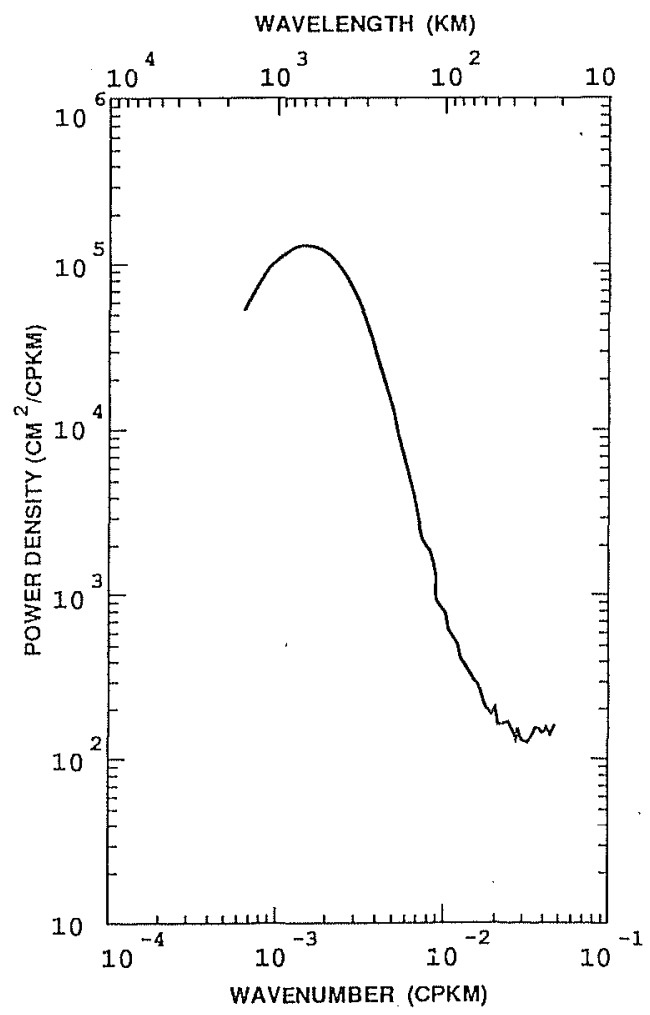

Fig. 2a. Example of along-track wave number spectrum of sea surface height. A noise level of around $150 \mathrm{~cm}^{2} \mathrm{cycle}^{-1} \mathrm{~km}$ dominates the signal up to a wavelength of $60 \mathrm{~km}$. 


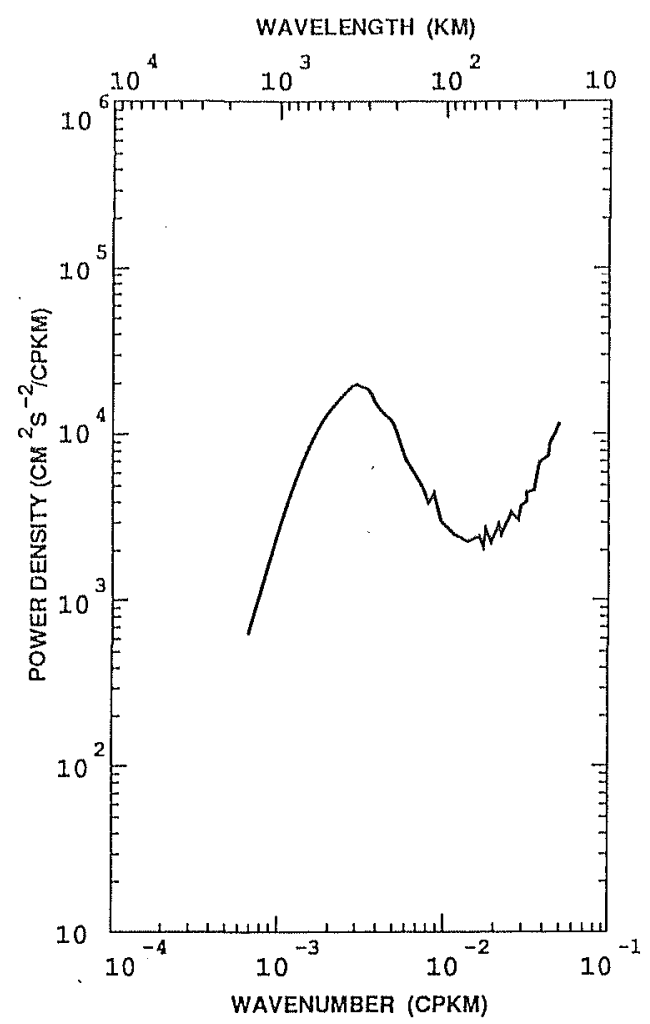

Fig. 2b. Same as Figure $2 a$, but for the transverse geostrophic velocity spectrum. Noise now seems to dominate the signal up to a wavelength of $100 \mathrm{~km}$.

therefore be filtered before estimating the ocean parameters. We decided to use a Lanczos filter [Hamming, 1977] with a cutoff wavelength of $60 \mathrm{~km}$; it has a very steep transfer function and thus affects only the desired range of wavelengths.

The geostrophic velocities were subsequently calculated from the slope of the SLA data using a centered difference scheme $(20 \mathrm{~km})$. As differentiation produces additional noise, the SLA data were first filtered with a cutoff wavelength of $100 \mathrm{~km}$. Figure $2 b$, which represents the transverse geostrophic velocity spectrum $F_{1}(k)\left(F_{1}(k)=\right.$ $g^{2} / f^{2}(2 \pi k)^{2} E_{1}(k)$, where $f$ is the Coriolis parameter and $g$ is gravity), shows, indeed, that the velocity signal is still noisy for wavelengths shorter than $100 \mathrm{~km}$. A cutoff wavelength of $100 \mathrm{~km}$ (rather than $60 \mathrm{~km}$ ) is also more consistent with our $20-\mathrm{km}$ slope calculation.

Note that the spectra shown in Figure 2 are one-side spectra, i.e., that $\int_{0}^{\infty} E_{1}(k)$ is the variance of SLA and $\int_{0}^{\infty} F_{1}(k)$ is the variance of geostrophic velocities. In the following, we will adopt this convention.

\section{VARIABILITY OF SLA AND OF Geostrophic Velocity}

We first calculated the altimetric height and geostrophic velocity variabilities. They can give useful information on spatial scales since the ratio of one to the other is related to the spatial scales of the mesoscale variability (see section 4.2.1). The estimates of eddy kinetic energy (EKE) deduced from Geosat were also compared with those obtained by surface drifters. This provides a means of evaluating the
Geosat contribution and the suitability of its spatial and temporal sampling for investigating mesoscale variability.

The SLA or velocity data $\left(d_{i}\right)$ derived along each track are first assembled in $2^{\circ}$ latitude by $2^{\circ}$ longitude bins. Variability $v_{\text {est }}^{2}$ is calculated over each bin, together with its associated error e (Gaussian assumptions):

$$
\begin{gathered}
v_{\mathrm{cst}}^{2}=\frac{1}{n} \sum_{i=1}^{n} d_{i}^{2} \\
e^{2}=\left\langle\left(v_{\mathrm{est}}^{2}-v^{2}\right)^{2}\right\rangle=\frac{2}{n_{i}} v^{4} \approx \frac{2}{n_{i}} v_{\mathrm{est}}^{4}
\end{gathered}
$$

where the angle brackets stand for mathematical expectation; $n$ is the number of data measurements over each bin, and $n_{i}$ is the number of independent estimates, derived on the assumption that one cycle in three is independent and that spatial decorrelation is $100 \mathrm{~km}$. These values correspond chiefly to the first zero crossings of temporal and spatial autocorrelation functions of SLA as found by P. Y. Le Traon and M. Ollitrault (Description of an eddy west of the Mid Atlantic Ridge, submitted to Joumal of Marine Research, 1990) and as calculated in section 4.2 from spatial autocorrelation functions.

Objective analysis [Bretherton et al., 1976] is then applied to adjacent bins to smooth out small-scale features. The covariance functions of the objective analysis are Gaussian, with an $e$-folding distance of $2^{\circ}$ in latitude and $3^{\circ}$ in longitude. The error map for the estimate is also calculated.

The map of the SLA variability (rms) (Plate 1) shows amplitudes from $4 \mathrm{~cm}$ to $30 \mathrm{~cm}$. The highest values are associated with the Gulf Stream and its extensions (North Atlantic Current). Outside these areas of strong mean current, smaller values are observed, particularly east of the Mid-Atlantic Ridge where amplitudes are, generally, below 5 $\mathrm{cm}$. This map is in agreement with that of Zlotnicki ef al. [1989], who used only 1 year of data, instead of 2 in our case. This suggests that most of the SLA variability is resolved in 1 year.

The geostrophic velocity variability obtained from altimetry represents the EKE, assuming isotropy. Plate 2 shows two EKE maps, one obtained by Geosat and the other from drifting buoy data of which almost all were gathered by Richardson [1983] (see Le Traon [1990] for an exact description of the data set). The two sets of data were processed in the same way (averaging across bins, and objective analysis). Note that this calculation removes small-scale structures, which explains the difference between our drifting buoy EKE map and Richardson's [1983] map. Agreement between the two types of measurements is very good, both regarding structures and with regard to the associated values. The ratio between the estimates confirms this agreement, since the mean ratio $\langle R\rangle=\left\langle\mathrm{EKE}_{\text {buoys }} / \mathrm{EKE}_{\mathrm{Gcosal}}\right\rangle$ (where the angle brackets signify spatial averaging on bins with rms errors below 50\%) is around I with a standard deviation of 0.4. Moreover, most of the (small) discrepancies can be explained by the error estimates $\sigma_{\text {EKE }}$ burs and $\sigma_{\mathrm{EKE}_{\mathrm{Cu} \text { a }}}$ (as given by the objective analysis), since the mean relative error $\left\langle\left|\mathrm{EKE}_{\text {buoys }}-\mathrm{EKE}_{\mathrm{Geosat}}\right|\left(\sigma_{\mathrm{EKE}}^{2} \mathrm{E}_{\text {tuuy }}\right.\right.$ $\left.\left.+\sigma_{E K E_{\text {(ien:il }}}^{2}\right)^{-1 / 2}\right\rangle$ is equal to around 1 . The difference between $\mathrm{EKE}_{\mathrm{Geosat}}$ and $\mathrm{EKE}_{\text {buoys }}$ shows, however, positive values of the order of $600-800 \mathrm{~cm}^{2} \mathrm{~s}^{-2}$ in the Gulf Stream, which seem 


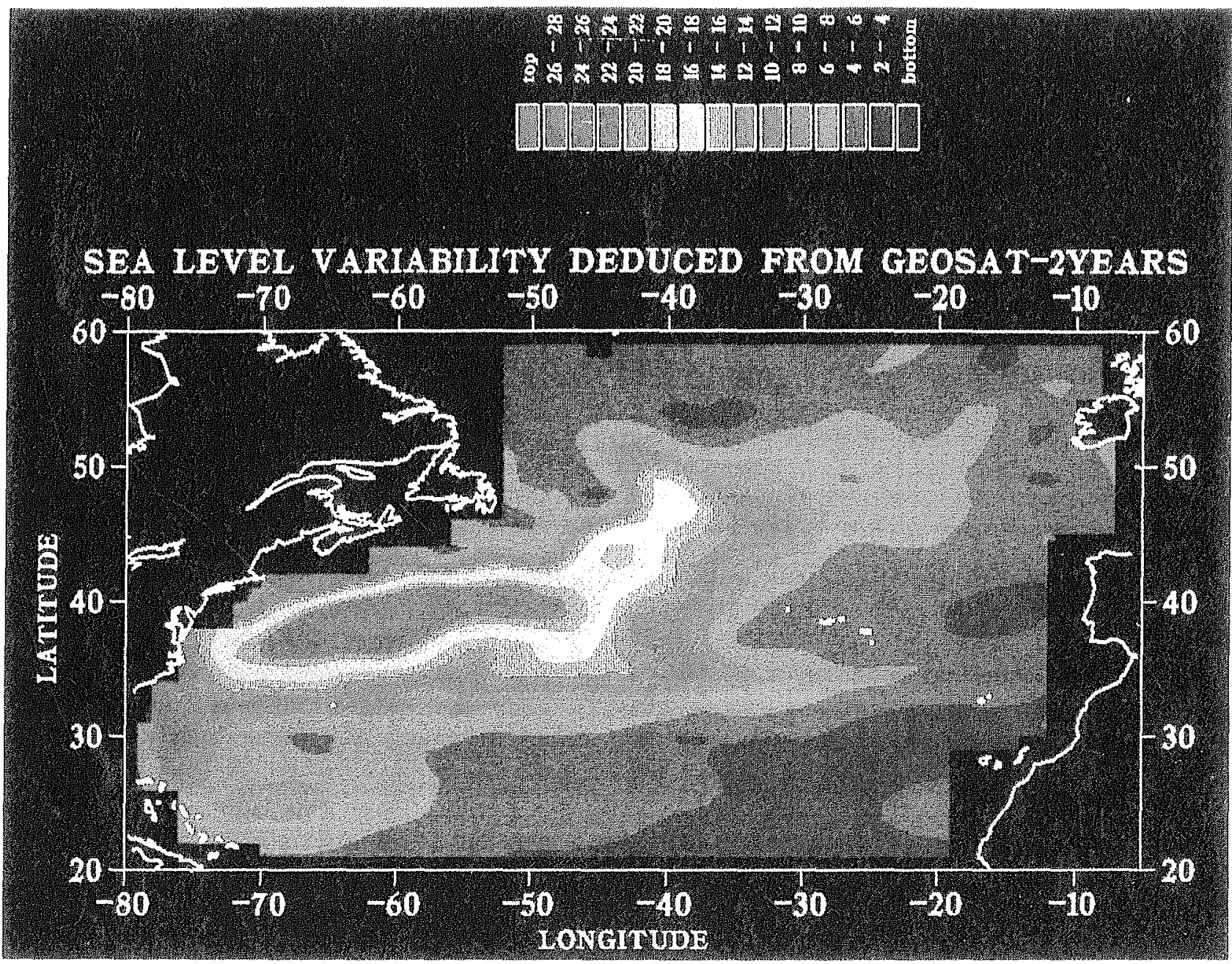

Plate 1. Root-mean-square of sea level anomaly obtained with 2 years of Geosat data. Objective analysis was applied to filter out small-scale features.

to be significant. A possible explanation is that energetic Gulf Stream rings, clearly identifiable in altimetric data, are largely removed by the filter used for drifter data [Richardson, 1983].

Surface drifters measure the Ekman component in addition to the geostrophic component and are subject to direct wind (and wave) effects. Richardson [1983] estimated this effect in the calculation of EKE, concluding that it was of the order of $100 \mathrm{~cm}^{2} \mathrm{~s}^{-2}$, which therefore does not contradict the agreement between the two measurements.

The results can be compared with those obtained by Daniault and Ménard [1985] from the Seasat data and the FGGE (First Global GARP Experiment) buoys in the Southern Ocean. They found a mean ratio of buoy EKE to Seasat EKE of 4, with a standard deviation of 2.3. This effect was mainly due to Seasat temporal sampling (6-24 days), since after temporal filtering of the buoy velocities the ratio had a mean value of 1.3 and a standard deviation of 1 .

The agreement obtained with Geosat data is related to its better temporal sampling (34-730 days) of mesoscale variability. This is particularly encouraging for the rest of the study and clearly shows the suitability of Geosat for the observation of mesoscale phenomena.

\section{Spatial Scales}

\subsection{Method}

To describe the spatial scales for different parts of the North Atlantic basin, we divided each of the four strips described in section 2, in turn, into groups of $10^{\circ}$ latitude by $10^{\circ}$ longitude. We then assigned each of the groups a two-figure number, the first figure giving the strip number $\left(2-5\right.$ for latitudes $\left.20^{\circ}-50^{\circ} \mathrm{N}\right)$ and the second the longitude $(0-5$ for $10^{\circ}-60^{\circ} \mathrm{W}$ ) (Figure 3 ). We considered 122 ascending and 123 descending tracks of $1500 \mathrm{~km}$ length, which gives an average of around 13 tracks per group (Figure 1). The $1500-\mathrm{km}$ length of the tracks limited the investigation of mesoscale variability to wavelengths shorter than $1500 \mathrm{~km}$. This limitation is due to our present knowledge of the satclite orbit and tides, which are the main sources of long-wavelength errors.

We then calculated the wave number spectra (and corresponding autocorrelation functions) by assembling the tracks in each group and calculating a mean spectrum per group. We calculated the spectra along each profile by FFT (last Fourier transform) on the profile heights. We applied a cosine-bell taper to the first and last $10 \%$ of the profile 


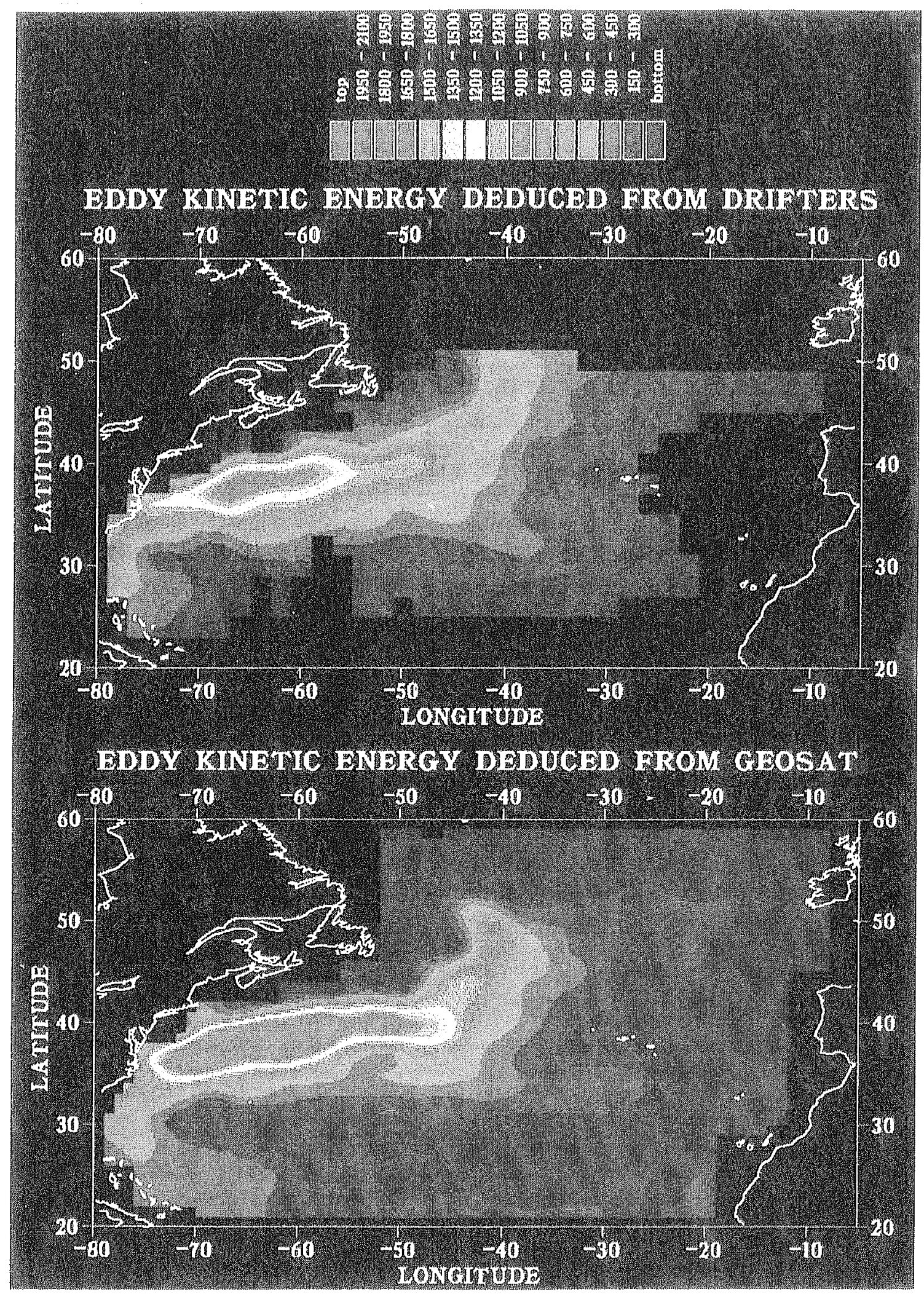

Plate 2. (Bottom) Eddy kinetic energy deduced from Geosat datal under the assumption of isotropy. The 2 years of Geosat data have been used. and objective analysis was applied to filter out small-scale features. (Top) Eddy kinetic energy deduced from driting buoy data. The same objective analysis as for Geosat data was applied.

heights to reduce side lobe power leakage. The number of degrees of freedom in this estimate is assumed to be equal to $2[1+(N T-1) / 3][1+(N C Y-1) / 3]$, where NT is the number of tracks used and NCY the number of cycles on each track. This assumes that one cycle in three (5l days) is independent and that one track in three is independent $(\approx 300$ $\mathrm{km})$. These are only crude estimates of the number of degrees of freedom, since neighboring tracks are differently 


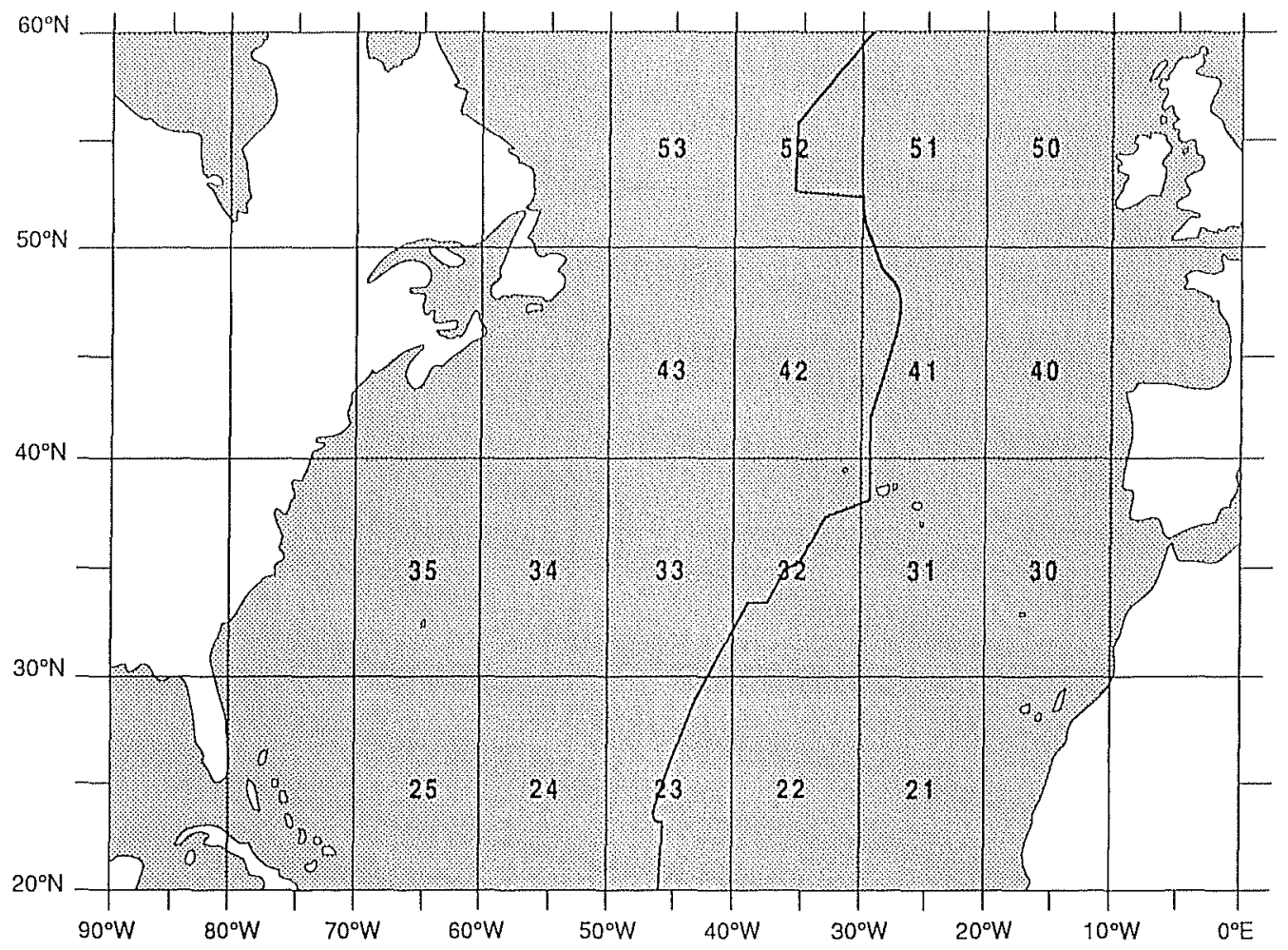

Fig. 3. Positions of groups corresponding to $10^{\circ}$ (latitude) $\times 10^{\circ}$ (longitude) areas where wave number spectra and autocorrelation function have been systematically calculated. Position of the Mid-Atlantic Ridge is also shown.

correlated for different wave numbers and the correlation of cycles on a given track will depend on the frequency-wave number spectrum. However, by choosing a decorrelation of one track in three, which is around 3 times the actual decorrelation length of SLA measurements, we have probably taken sufficient account of error factors. The mean number of tracks per group is around 13 , and the mean number of cycles per track is around 30 (most of the tracks are only partially complete). This gives an average of 100 degrees of freedom, which corresponds to a precision of around $15 \%$ for our estimation. The precision on spectral slopes can also be estimated: a spectral slope between 150 $\mathrm{km}$ and $300 \mathrm{~km}$ (six independent spectral estimations) can be estimated to within \pm 0.6 .

\subsection{Spatial Scales}

We first calculated the mean spectra of the ascending and descending tracks separately in order to reveal any anisotropic effect. Note, however, that the geometric configuration of the tracks does not allow any possible dominance of zonal scales to be detected. Most spectra are generally not significantly different, given the confidence intervals used. In general, the assumption of isotropy is not refuted, thus lending support to the choice of averaging ascending and descending spectra together. However, it seems that significant differences can be observed for some groups situated near the Gulf Stream (see groups 33 and 43 in Figure 4) as well as in regions of low eddy activity (see groups 40, 41, and 53 in Figure 4). For groups situated near the Gulf Stream, the differences occur principally at wavelengths longer than 300 $\mathrm{km}$ and could be related to the way Gulf Stream meanders develop. For other groups, differences are also observed for long wavelengths (40 and 53), although group 41 shows differences in the 50 - to $150-\mathrm{km}$ wavelength band. We do not presently have a satisfactory explanation of this result.

4.2.1. Comparison of wave number spectra. The mean unfiltered wave number spectra per group are shown in Figures $5 a-5 d$. The general shape of the spectra can be described as follows: a white noise level of around $150 \mathrm{~cm}^{2}$ cycle ${ }^{-1} \mathrm{~km}$ visible up to scales increasing from $30 \mathrm{~km}$ in the north to $60 \mathrm{~km}$ in the south; an "intermediate regime," sometimes nonexistent, up to $100-200 \mathrm{~km}$ from north to south, where spectra are red with weak slopes of around -1 ; a band of wavelengths with red spectra and well-defined slopes; and then a break in the slope in most groups occurring after a peak wavelength of $200-500 \mathrm{~km}$ from north to south. We shall now provide a more detailed description of these last three features.

The slopes of the red part of the spectra are generally between -2 and -4 . The steepest slopes are observed at the western part of the basin and are associated with energetic areas, while the weaker slopes are found east of the MidAtlantic Ridge where eddy activity is lower. Slopes of -1 to -2 are obtained for groups, east of strip 2 (groups 21 and 22) and group 30, which are the least energetic groups in our study area.

The peak wavelengths corresponding to breaks in the spectrum slopes and the shape of the spectra for longer wavelengths are useful parameters for the study of eddy dynamics (see section 5). These peak wavelengths (vertical arrows in Figures $5 a-5 d$ ) decrease as latitude increases: the mean is around $500 \mathrm{~km}$ between $20^{\circ}$ and $30^{\circ} \mathrm{N}$ (strip 2), 400 $\mathrm{km}$ between $30^{\circ}$ and $40^{\circ} \mathrm{N}$ (strip 3), $300 \mathrm{~km}$ between $40^{\circ}$ and $50^{\circ} \mathrm{N}$ (strip 4), and $200 \mathrm{~km}$ between $50^{\circ}$ and $60^{\circ} \mathrm{N}$ (strip 5). For groups 21,22 , and 30 , no significant break is observed: the slight decrease in the spectral density at $1500 \mathrm{~km}$ 

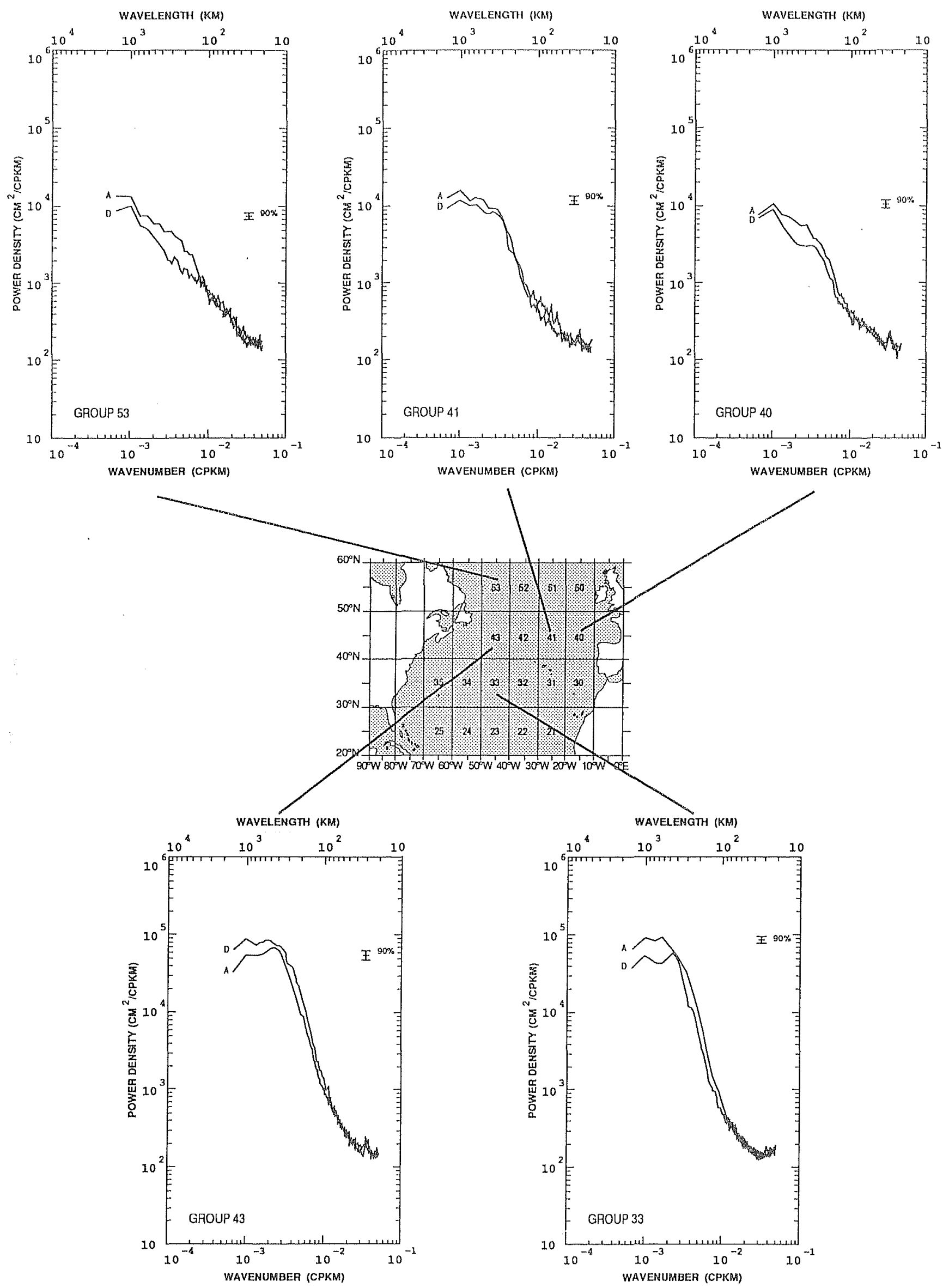

Fig. 4. Spectra of ascending (A) and descending (D) tracks for groups which show the most significant differences. 

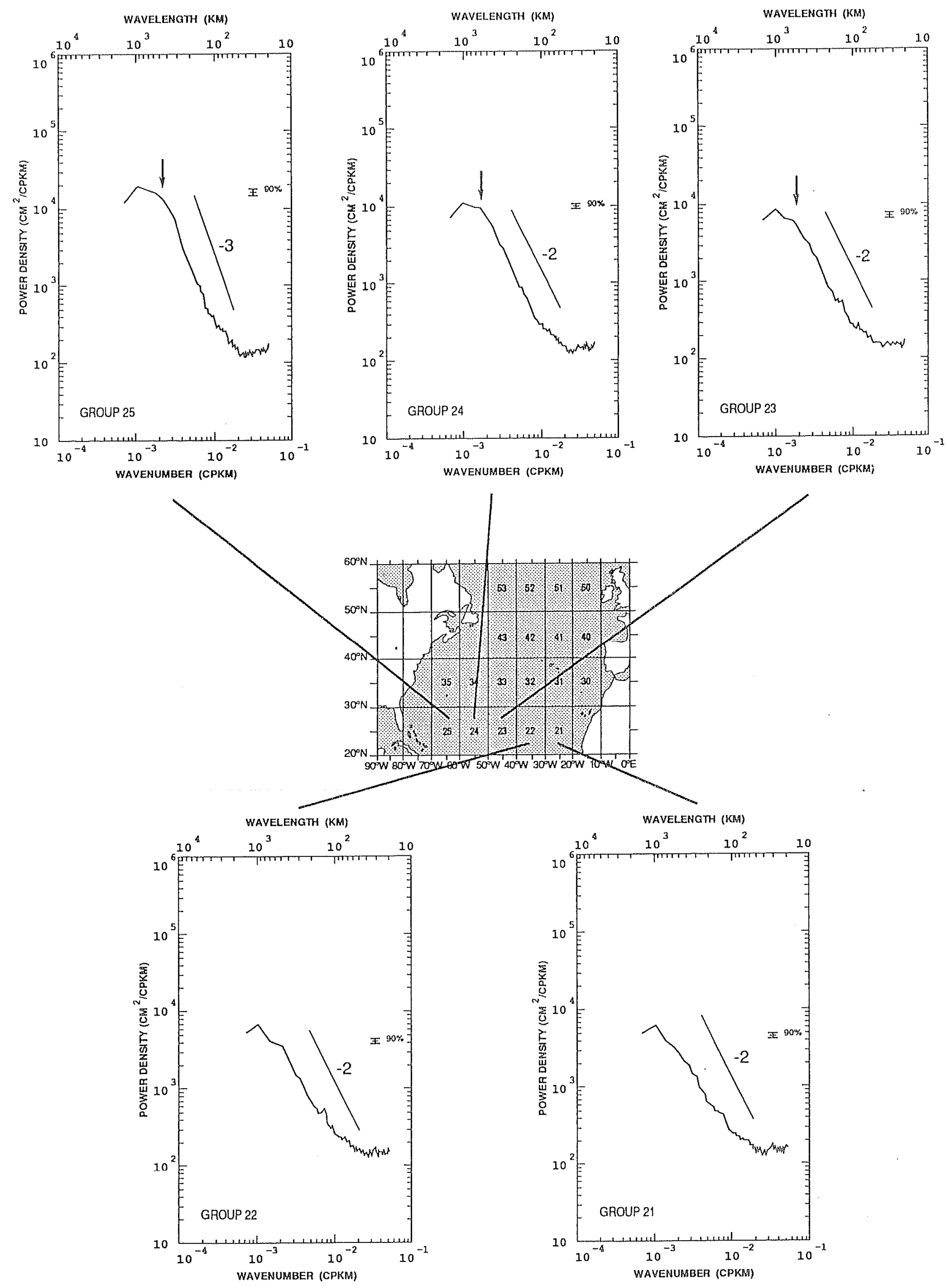

Fig. $5 a$. Mean wave number spectra for groups between $20^{\circ} \mathrm{N}$ and $30^{\circ} \mathrm{N}$ (strip 2). 

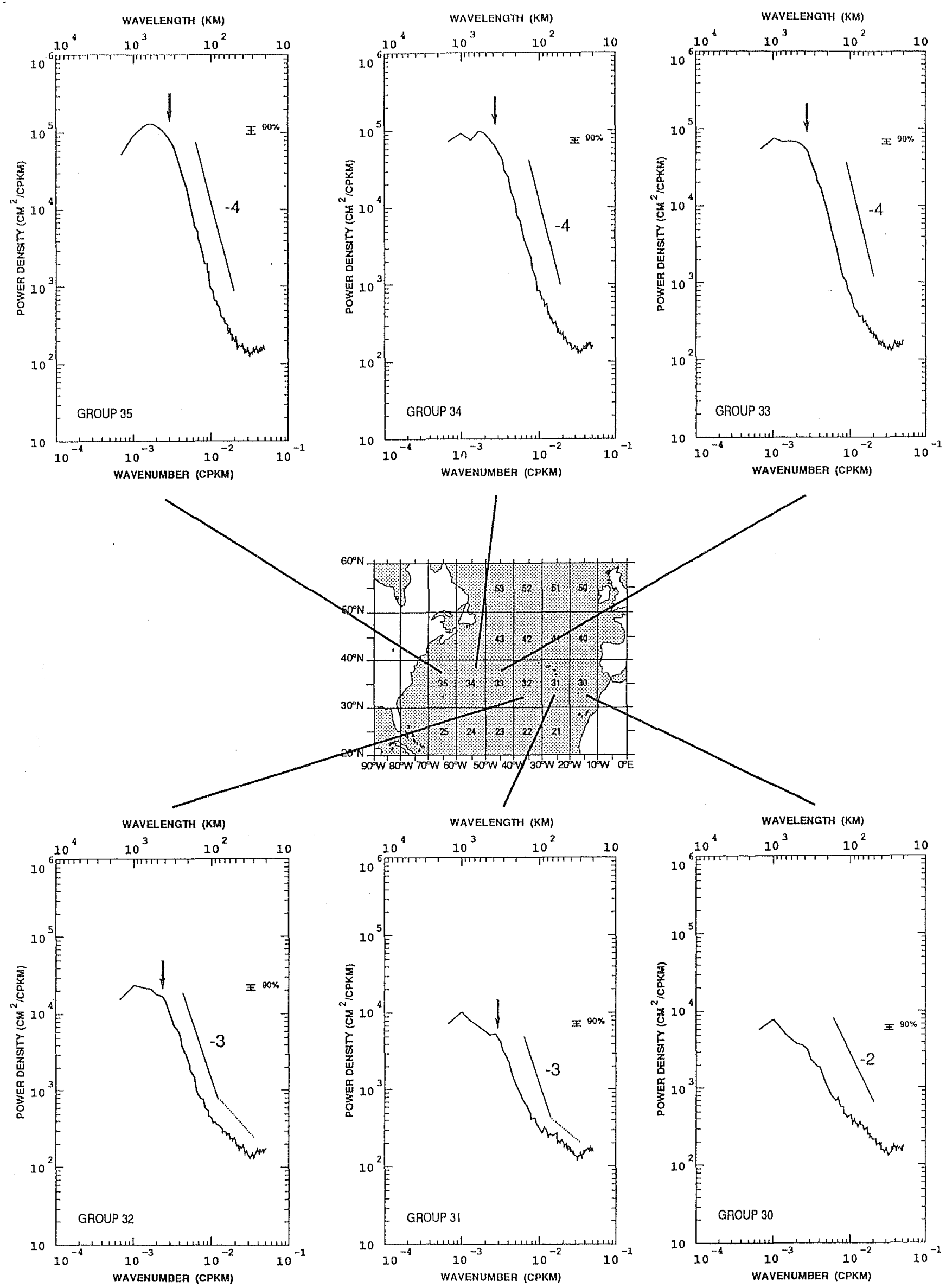

Fig. 5b. Mean wave number spectra for groups between $30^{\circ} \mathrm{N}$ and $40^{\circ} \mathrm{N}$ (strip 3 ). 

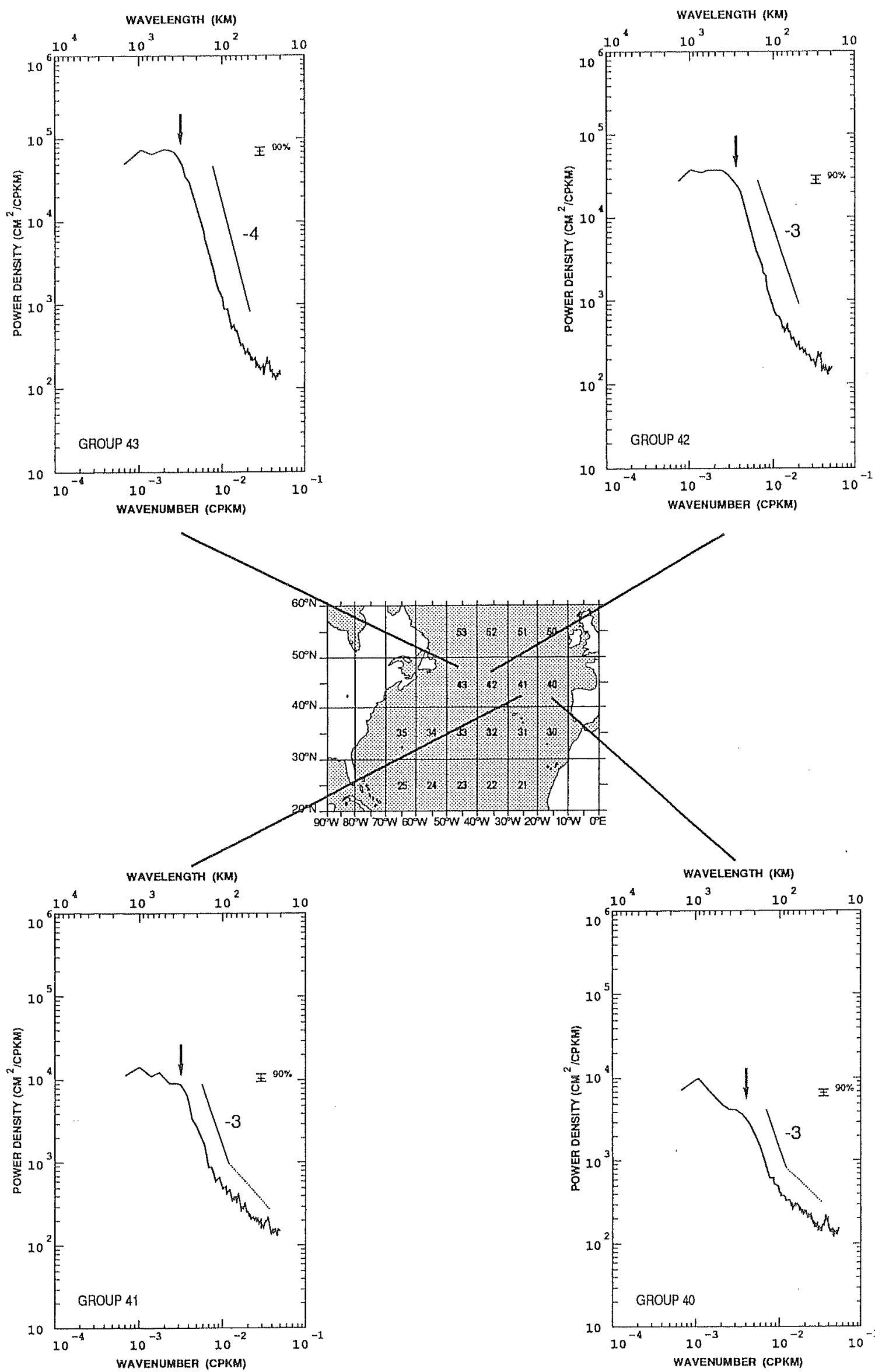

Fig. 5c. Mean wave number spectra for groups between $40^{\circ} \mathrm{N}$ and $50^{\circ} \mathrm{N}$ (strip 4$)$. 

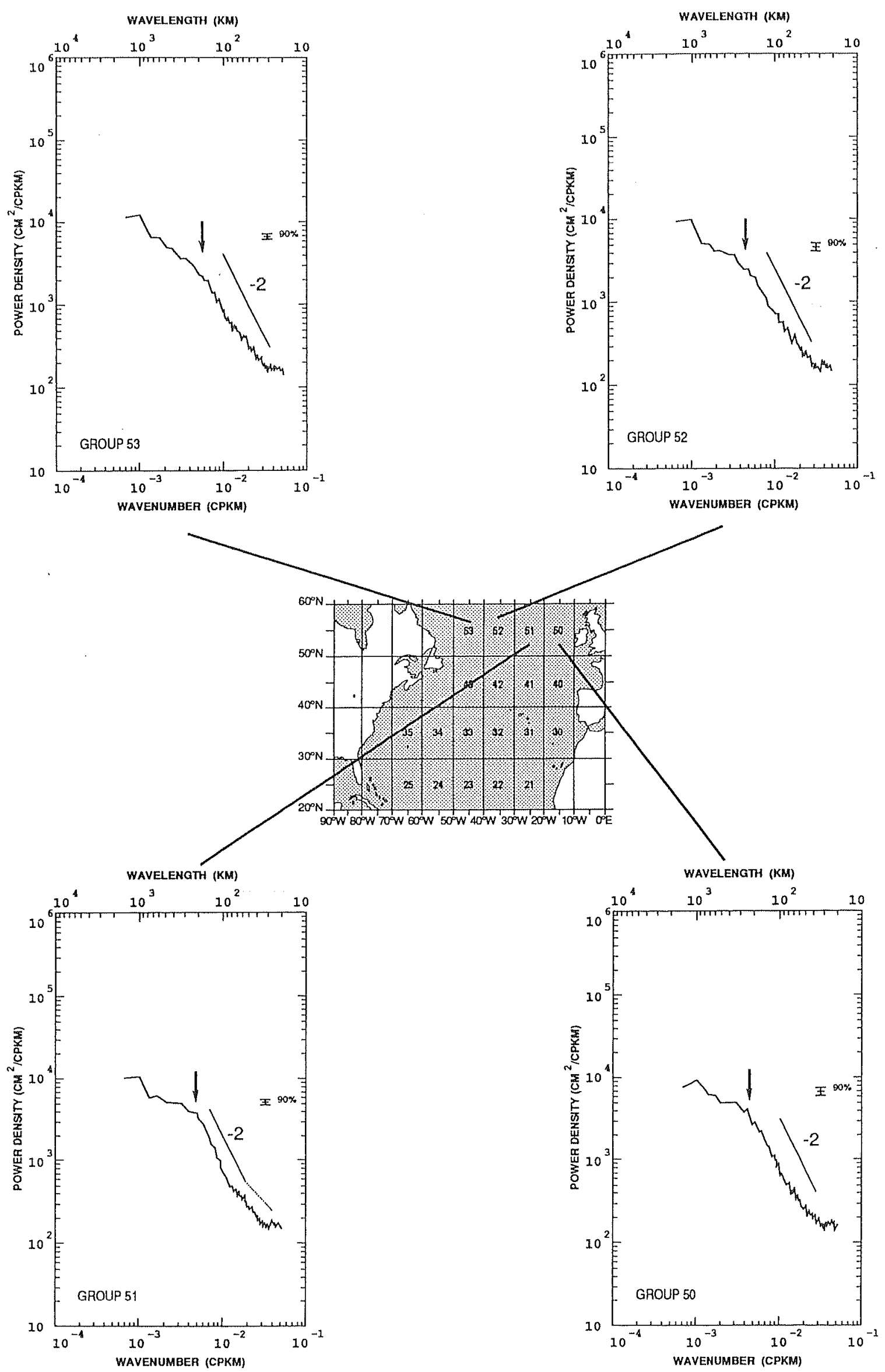

Fig. $5 d$. Mean wave number spectra for groups between $50^{\circ} \mathrm{N}$ and $60^{\circ} \mathrm{N}$ (strip 5). 
wavelength (which can be observed for all spectra) is mostly caused by the procedure used for removing the orbit error. In the following discussion this spectrum estimation will not be considered significant. After the peak wavelength the spectra are "bluer" in the energetic areas.

These spectra $E_{1}(k)$ are one-dimensional spectra of the wave number vector along-track component. Thus for a wavelength $k^{-1}$ these spectra in the along-track direction contain "contributions" from all wavelengths shorter than $k^{-1}$ whose wave number vector components (not parallel to the track) along the satellite ground track are $k^{-1}$. However, assuming isotropy, these one-dimensional spectra can be used to calculate the scalar spectra in wave number $E_{0}(k)$ such that $E_{0}(k)=2 \pi k E_{2}\left(k_{1}, k_{2}\right)$, where $E_{2}\left(k_{1}, k_{2}\right)$ is the two-dimensional spectrum and where $k_{1}^{2}+k_{2}^{2}=k^{2}$ (see, for example, $F_{\| l}$ [1983]). The above behavior is then accentuated, since $E_{1}(k)$ is a weighted integral of $E_{0}(k)$. Indeed,

$$
E_{1}(k)=\frac{2}{\pi} \int_{k}^{\infty} \frac{E_{0}\left(k_{1}\right)}{\left(k_{1}^{2}-k^{2}\right)^{1 / 2}} d k_{1}
$$

Inversely, $E_{0}(k)$ can be deduced from $E_{1}(k)$ as follows:

$$
E_{0}(k)=-\int_{k}^{\infty} \frac{k_{1} d E_{1}\left(k_{1}\right) / d k_{1}}{\left(k_{1}^{2}-k^{2}\right)^{1 / 2}} d k_{1}
$$

The kinetic energy spectrum $F_{0}(k)$ is then directly related to $E_{0}(k)$ as follows:

$$
F_{0}(k)=\frac{g^{2}}{2 f^{2}}(2 \pi k)^{2} E_{0}(k)
$$

We used (2) and then (3) to calculate $E_{0}(k)$ and $F_{0}(k)$ for groups 35 and 40 , which have different characteristics, spectrum $E_{1}(k)$ of group 35 being blue after the break and that of group 40 remaining red. This difference is considerably intensified in spectra $E_{0}(k)$ and $F_{0}(k)$ (Figures $6 a$ and $6 b$ ). Thus the shape of the spectra at longer wavelengths varies noticeably from one region to another. Two significant sets can be distinguished in terms of the shape of the spectra after the break: blue or white (e.g., groups 33, 35, 34, 43, and 42) and red (e.g., groups $31,40,41,50,51,52$, and 53). Spectra of strip 2 are probably in this last category, but this is more difficult to observe because the break occurs for longer wavelengths.

The third interesting characteristic observed in most of the groups east of the Mid-Atlantic Ridge (c.g., groups 31, 32, 40,41 , and 51 ) is a well-defined "intermediate regime," which in fact corresponds to an increase in energy between 50 and $150-200 \mathrm{~km}$ (see dotted lines in Figures $5 b, 5 c$, and $5 d$ ). This change of spectral slope, however, is not so clearly observed for groups west of the Mid-Atlantic Ridge.

These three main characteristics of spectra and their relation to eddy dynamics will be discussed in section 5 .

4.2.2. Autocorrelation functions and characterization of spatial scales. Figures $7 a-7 d$ show the autocorrelation functions $C(r) / C(0)$, where $C(r)$ is the autocovariance function obtained by inverse Fourier transform of the $60 \mathrm{~km}$ SLA filtered spectra. Most of these functions show negative lobes which are partly due to the procedure used to remove orbit error, which also removes oceanic signal at large wavelengths. To describe the different spatial scales, the integral of the square of the autocorrelation functions L2 (L2 =

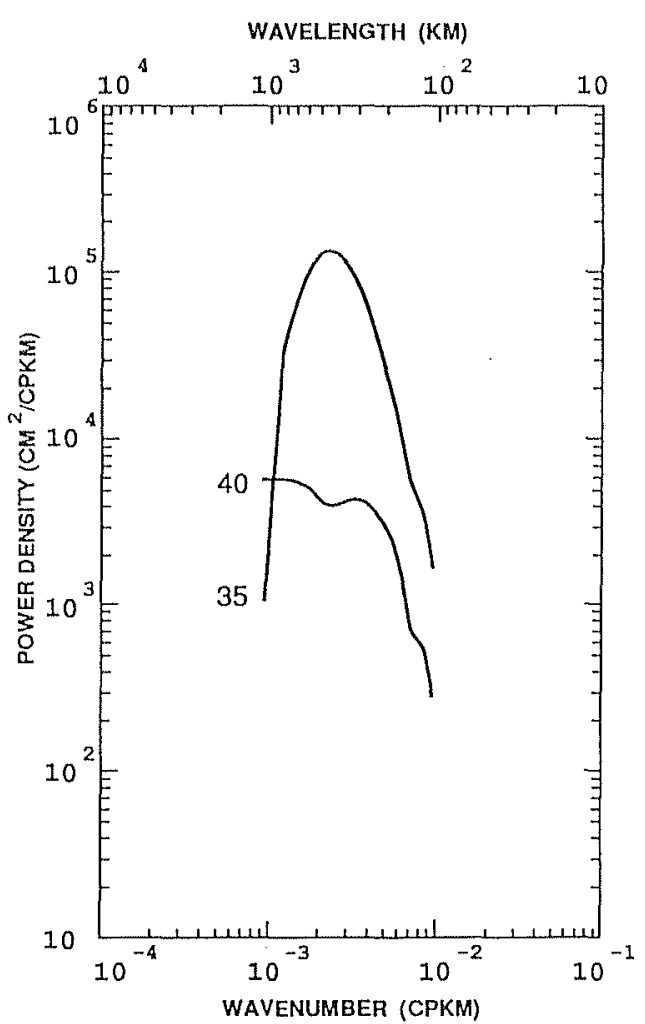

Fig. 6a. Mean scalar wave number spectra for groups 35 and 40 .

$\left.\int_{0}^{x} C^{2}(r) / C^{2}(0) d r\right)$ and the integral of the autocorrelation function for lag smaller than the first zero crossing $\mathrm{LI}(\mathrm{LI}=$ $\int_{0}^{z c^{\circ}} C(r) / C(0) d r$ ) were both calculated. When the functions have significant negative lobes, it is indeed preferable to calculate L2 (or L1) rather than the integral scale IS (IS =

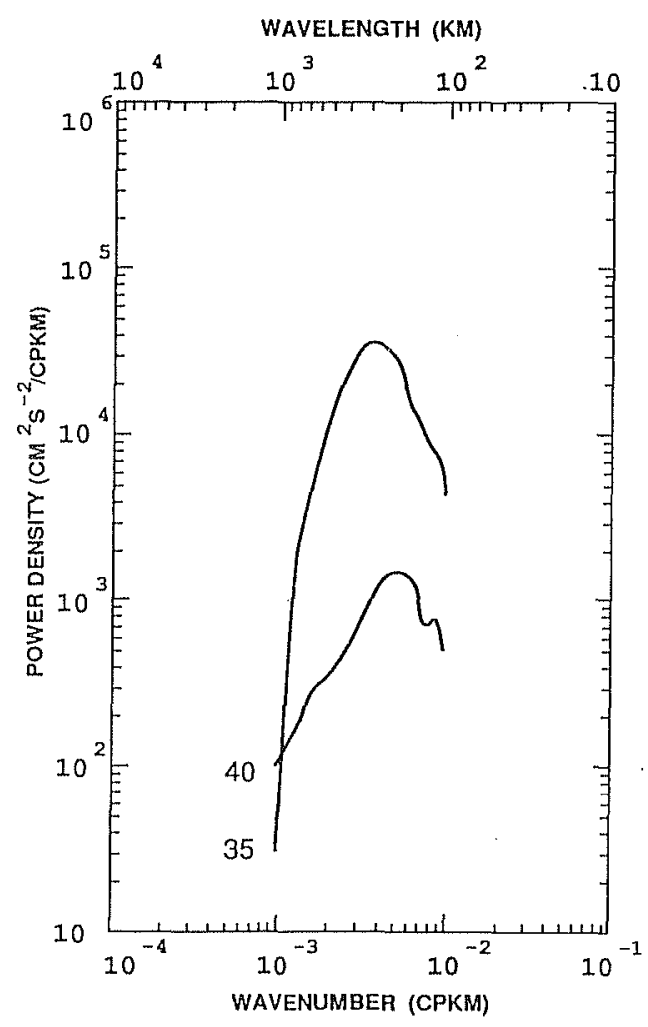

Fig. 6b. Mean kinetic energy spectra for groups 35 and 40 . 

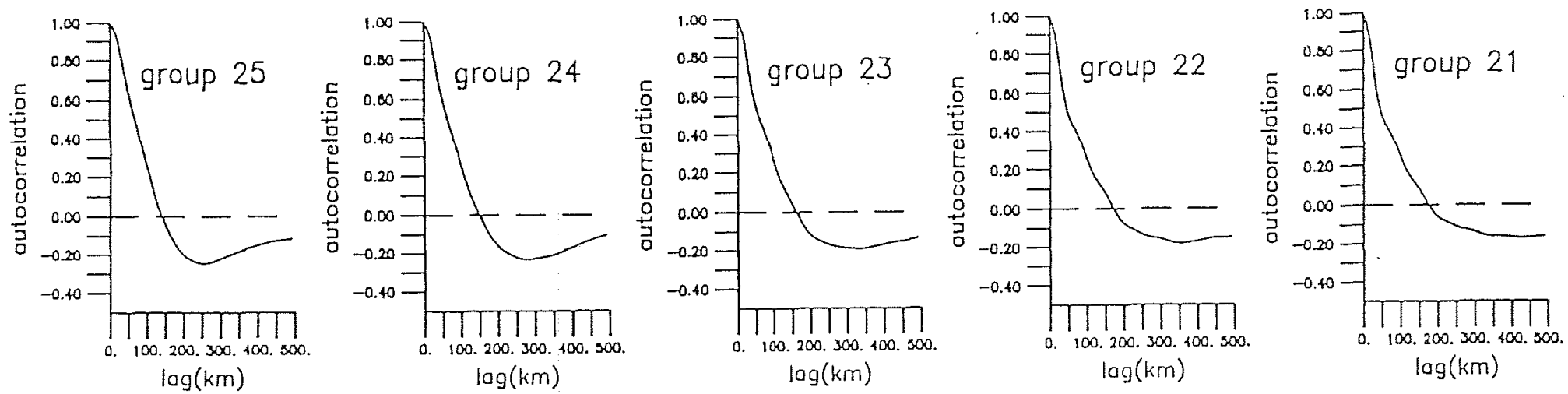

Fig. 7a. Mean autocorrelation functions for groups between $20^{\circ} \mathrm{N}$ and $30^{\circ} \mathrm{N}$ (strip 2).
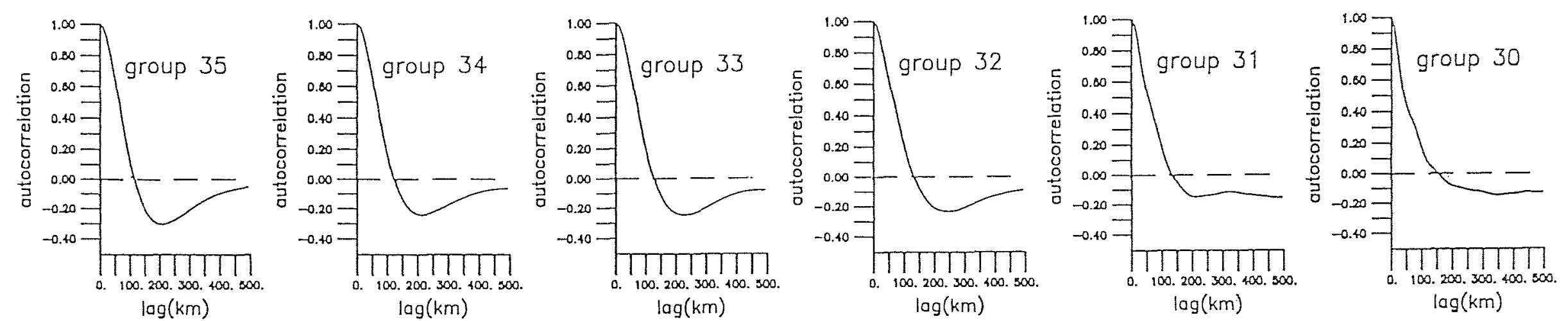

Fig. 7b. Mean autocorrelation functions for groups between $30^{\circ} \mathrm{N}$ and $40^{\circ} \mathrm{N}$ (strip 3). 

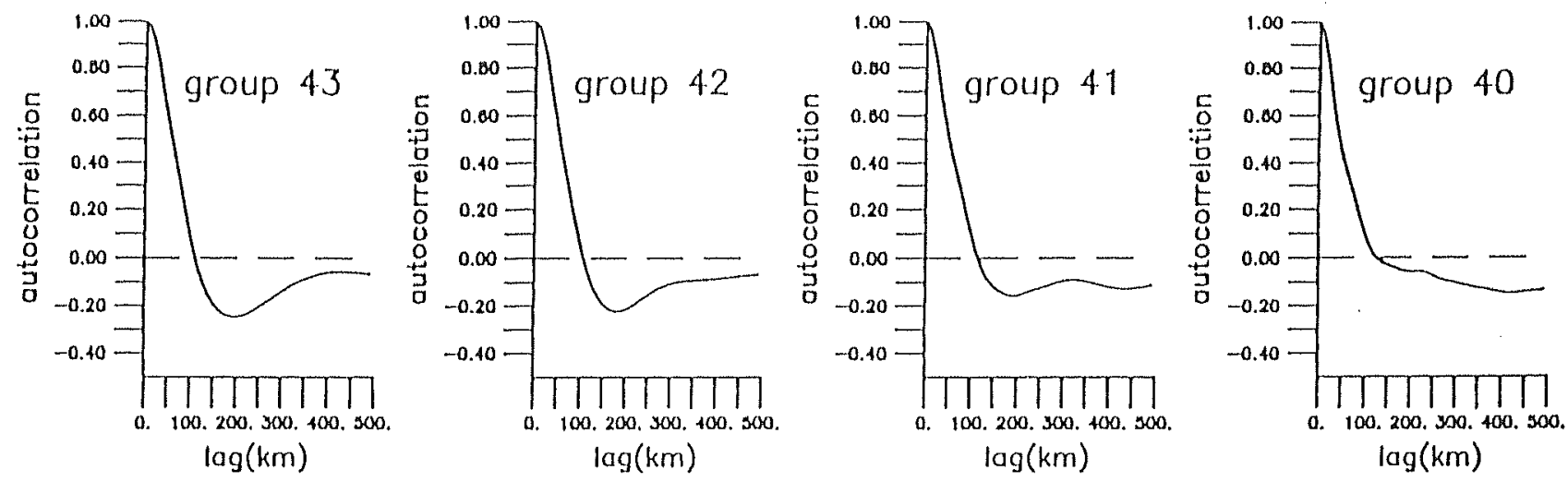

Fig. 7c. Mean autocorrelation functions for groups between $40^{\circ} \mathrm{N}$ and $50^{\circ} \mathrm{N}$ (strip 4).

$\left.\int_{0}^{\infty} C(r) / C(0) d r\right)$ to estimate a correlation length [Richman et al., 1977]. Note also that IS is equal to the along-track spectrum value at zero wave number and thus, due to long-wavelength errors, cannot be presently estimated.

We also calculated a mean wavelength defined by

$$
\langle k\rangle^{-1}=\int_{1500 \mathrm{~km}^{-1}}^{60 \mathrm{~km}^{-1}} E_{1}(k) d k\left(\int_{1500 \mathrm{~km}^{-1}}^{60 \mathrm{~km}^{-1}} k E_{1}(k) d k\right)^{-1}
$$

and $\alpha=(\operatorname{Var} u / \operatorname{Var} h)$, which is inversely proportional to $(f \lambda / g)^{2}$, where $f$ is the Coriolis parameter, $g$ is gravity, and $\lambda$ is a characteristic wavelength; $\lambda$ is the SLA autocorrelation function microscale length [e.g., Tennekes and Lumley, 1972] as it is related to the curvature of $C$ near the origin (it is the intercept of the parabola that matches $C(r)$ at the origin):

$$
\frac{C(r)}{C(0)} \approx 1-\frac{r^{2}}{\lambda^{2}} \quad \text { small } r
$$

i.e.,

$$
\frac{2}{\lambda^{2}}=-\frac{C^{\prime \prime}(0)}{C(0)}=\alpha\left(\frac{f}{g}\right)^{2}
$$

Table 1 shows values for these different parameters $L 1$, L2, $\lambda, \alpha$, and $\langle k\rangle^{-1}$. L2 is represented in Figure $8 a$ according to longitude and for each latitude strip. For comparison purposes, the first internal Rossby radii (IR) obtained by Emery et al. [1984] are shown in Figure $8 b$. The first internal Rossby radius is indeed an important parameter for the description of the spatial scales, since previous studies have shown that eddies appear to have spatial scales proportional to the first internal radius (see, for example, Mercier and Colin de Verdiere [1985]). The relation between the motion spatial scale $L$ and IR is given by the ratio $R=\mathrm{EKE} / \mathrm{EPE}$, where EPE is eddy potential energy, since $R$ is proportional to $(\mathrm{IR} / \mathrm{L})^{2}$ for quasi-geostrophic motions [Pedlosky, 1979].

The different characteristic scales (i.e., L1, L2, $\lambda$, and $\langle k\rangle^{-1}$ ) illustrate the same tendencies: apart from strip 2 and group 30, scales decrease regularly according to latitude. This variation, however, is smaller than for the first internal radii and is more related to variations in $f^{-1}$, as the nearly constant $\alpha$ value of 4 suggests. The scales of strip 2 (and group 30) are smaller than this simple rule of proportionality would imply, and scales between strip 2 and strip 3 can vary negatively with the internal radii. The corresponding $\alpha$ values are very different and larger than in the other regions, which also means that scales are smaller there. The proportionality of scales with $f^{-1}$ is, however, only approximate, since the scales also vary significantly over the same latitude strip: the appreciable westward increase observed in strips 2,3 , and 4 is actually comparable to the difference between adjacent strips.
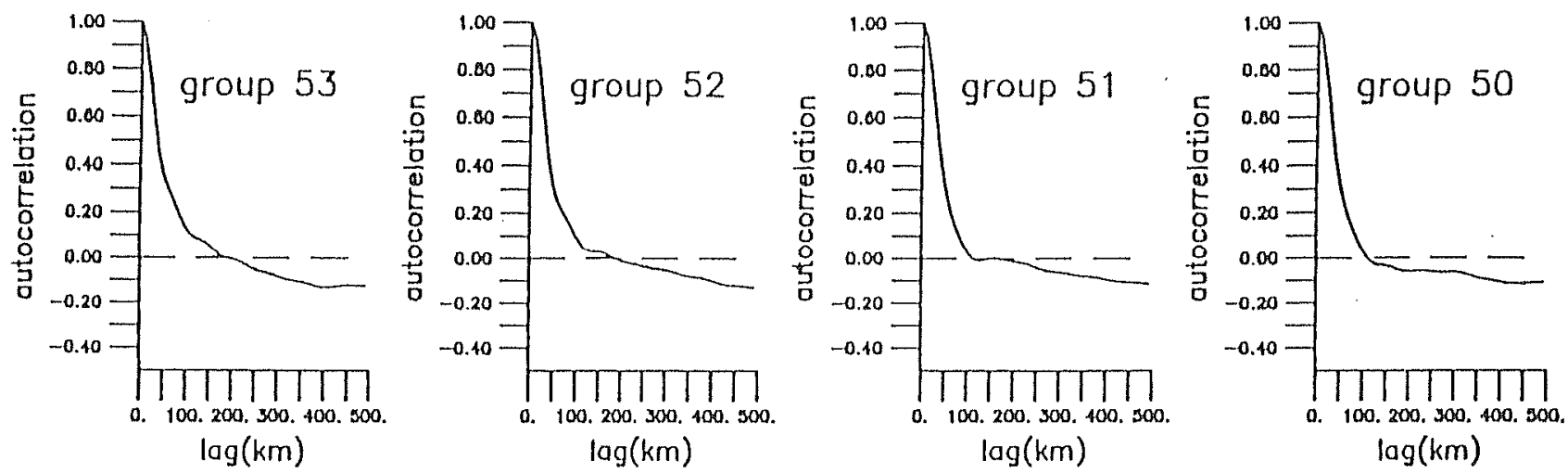

Fig. 7d. Mean autocorrelation functions for groups between $50^{\circ} \mathrm{N}$ and $60^{\circ} \mathrm{N}$ (strip 5). 
TABLE 1. Characteristic Spatial Scales for Each Group

\begin{tabular}{ccccc}
\hline Group & $\begin{array}{c}\text { L1, } \\
\mathrm{km}\end{array}$ & $\begin{array}{c}\text { L2, } \\
\mathrm{km}\end{array}$ & $\begin{array}{c}\lambda(\alpha), \\
\mathrm{km}\end{array}$ & $\begin{array}{c}\langle k\rangle^{-1} \\
\mathrm{~km}\end{array}$ \\
\hline 21 & 63 & 46 & $68(11.1)$ & 245 \\
22 & 65 & 48 & $69(10.6)$ & 260 \\
23 & 66 & 51 & $73(9.6)$ & 285 \\
24 & 67 & 56 & $76(8.7)$ & 315 \\
25 & 69 & 61 & $80(7.9)$ & 355 \\
30 & 58 & 41 & $66(6.3)$ & 240 \\
31 & 60 & 48 & $72(5.4)$ & 285 \\
32 & 66 & 58 & $79(4.4)$ & 350 \\
33 & 68 & 61 & $83(4.0)$ & 390 \\
34 & 66 & 59 & $80(4.2)$ & 380 \\
35 & 63 & 61 & $79(4.2)$ & 380 \\
40 & 52 & 40 & $65(4.2)$ & 255 \\
41 & 55 & 44 & $70(3.7)$ & 285 \\
42 & 56 & 48 & $71(3.6)$ & 325 \\
43 & 60 & 53 & $74(3.3)$ & 350 \\
50 & 42 & 32 & $57(4.1)$ & 225 \\
51 & 42 & 32 & $57(4.1)$ & 225 \\
52 & 46 & 32 & $58(4.0)$ & 215 \\
53 & 52 & 36 & $60(3.7)$ & 225 \\
\hline
\end{tabular}

\section{Validation and Discussion}

Both spectra and scales are significantly different from one region to another, to validate them, the different sources of error must now be examined. The results will then be compared with other similar calculations and with in situ measurements. They will then be interpreted in terms, of eddy dynamics by a comparison with models and with quasi-geostrophic theory.

\subsection{Major Sources of Error}

As noted in section 2, altimetric measurements of SLA are subject to many sources of error. For our mesoscale study, i.e., for wavelengths shorter than $1500 \mathrm{~km}$, the three major sources of error are sea state bias, wet tropospheric effects, and inverse barometer effects. Sea state bias and wet tropospheric errors are, indeed, only partially corrected, while error due to the barometer effect is not. These atmospheric effects are assumed to have spatial scales greater than mesoscale ocean movements but may resemble the ocean signal at larger scales (i.e., at the end of the mesoscale spectra). This is precisely where the shapes of the spectra

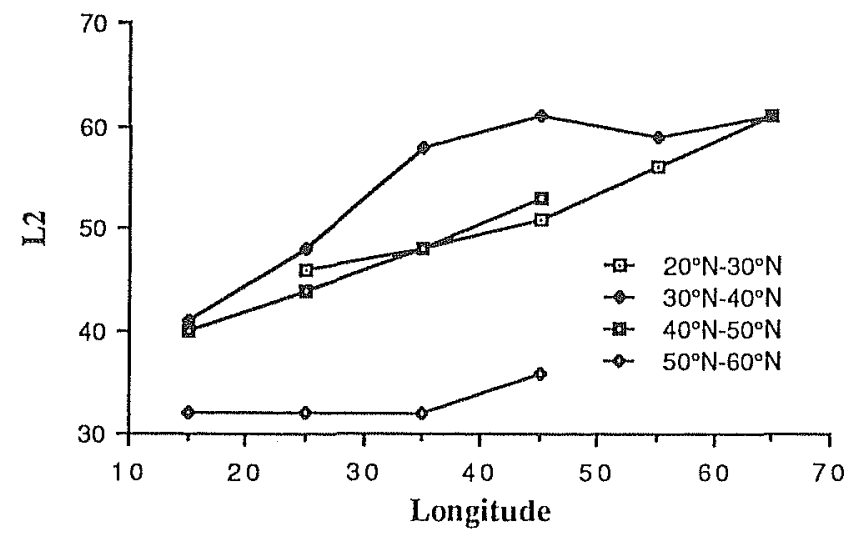

Fig. 8a. Evolution of $\mathrm{L} 2=\int_{0}^{x} C(r)^{2} / C(0)^{2} d r(C$ is the SLA autocovariance function) according to longitude for strips $2,3,4$, and 5 .

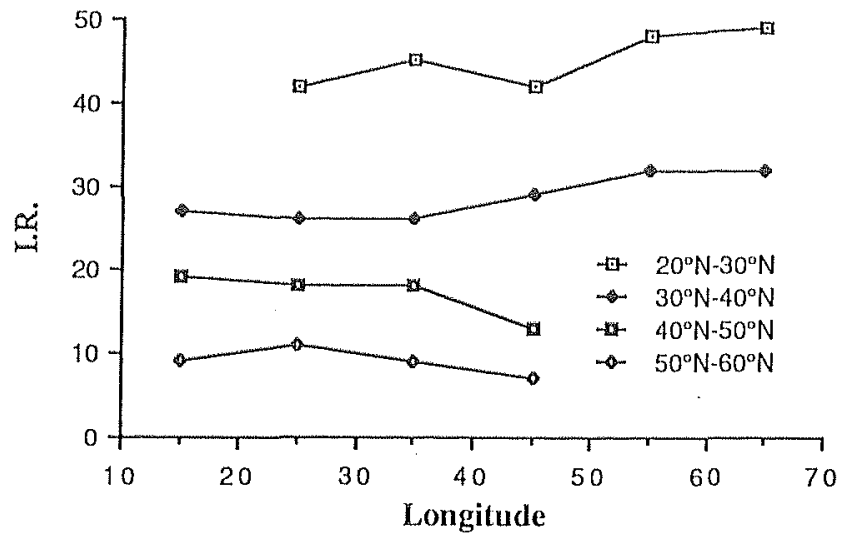

Fig. 8b. Evolution of internal Rossby radii according to longitude for strips $2,3,4$, and 5 .

were shown in section 4 to be significantly different from one region to another.

Sea state bias effects do not appear to be a significant source of error, since even in areas with large $H_{1 / 3}$ values, the correction level (after bias and slope adjustments) is, in our wavelength band, lower than the signal level. Thus the SLA spectra are well above those corresponding to $2 \%$ of $H_{1 / 3}$, which is the correction generally used for $H_{1 / 3}$ effects in Geosat data. This can be seen in Figure 9 (reproduced from D. Jourdan, C. Boissier, and J. F. Minster, How geophysical corrections interfere with oceanic mesoscale variability as observed by altimetry, submitted to Journal of Geophysical Research, 1990), where these two spectra, obtained with an ensemble of Geosat tracks over a 2-month period in the northeast Atlantic $\left(45^{\circ}-60^{\circ} \mathrm{N}, 15^{\circ}-35^{\circ} \mathrm{W}\right)$, are compared.

The wet tropospheric error correction, as given in the GDRs, is more problematic but is also probably below the ocean signal. This conclusion was also reached by $F u$ [1983] for Seasat altimeter measurements. The comparison of oce-

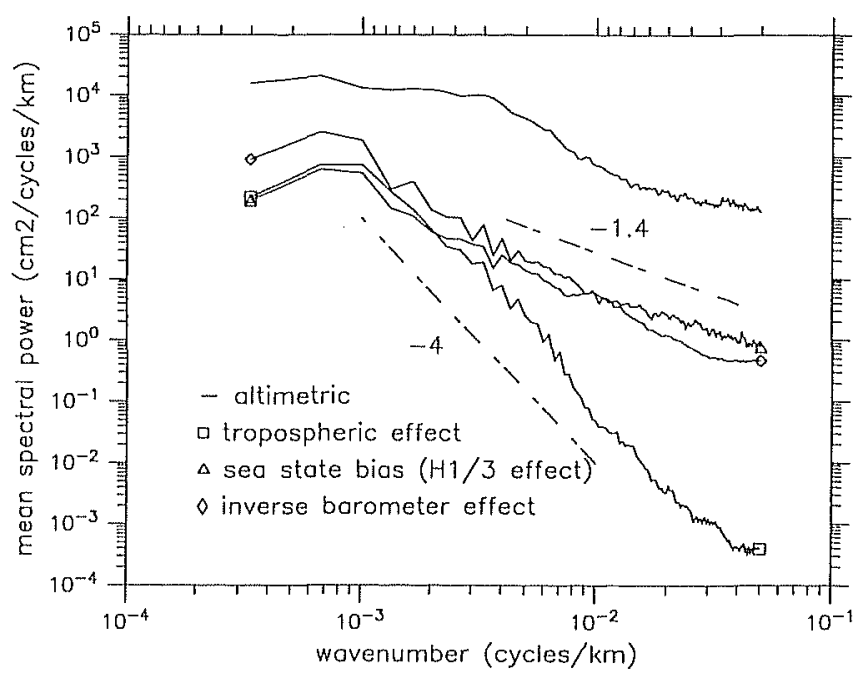

Fig. 9. Spectra of $2 \%$ of $H_{1 / 3}$, tropospheric, and inverse barometer correction compared to the altimetric signal spectrum in the northeast Atlantic (reproduced from D. Jourdan, C. Boissier, and J. F. Minster, How geophysical corrections interfere with oceanic mesoscale variability as observed by altimetry, submitted to Journal of Geophysical Research, 1990). 
anic spectra with those of wet tropospheric error obtained with the available scanning multichannel microwave radiometer (SSMR) data showed, indeed, that oceanic spectra for both high- and low-energy areas were not significantly affected for wavelengths shorter than $1000 \mathrm{~km}$. As Geosat oceanic spectra contain more energy for long wavelengths than those of Seasat [Fu and Zlotnicki, 1989], they should be even less affected. Recent results [Jourdan et al., 1990] have confirmed this hypothesis and shown that in the northeast Atlantic this correction was also considerably below the ocean signal for wavelengths shorter than $1500 \mathrm{~km}$. This can also be seen in Figure 9, which summarizes the results of Jourdan et al. [1990] as far as water vapor correction is concerned. In this figure, the water vapor correction spectrum has been calculated with 2 months of data from a high-resolution $(\approx 30 \mathrm{~km})$ meteorological model (Peridot French Météorologie Nationale model) and is well below the altimetric one. This result should extrapolate well for midlatitude regions. Bisagni [1989] reached similar conclusions for wet tropospheric corrections in the northwest Atlantic.

The inverse barometer effect remains the chief source of uncertainty because the ocean response to atmospheric pressure loading is not well understood. However, standard inverse barometer correction $\left(\delta_{\mathrm{ibc}}=9.95 \times 10^{-3}\left(P_{a}-\right.\right.$ 1013.3), where $P_{a}$ is atmospheric surface pressure) has a wave number spectrum which is below the mesoscale oceanic spectrum (Figure 9). In this figure, $\delta_{\mathrm{ibc}}$ values were obtained with 2 months of atmospheric surface pressure data derived from the Peridot model. Note that the dry tropospheric effect is the same as the inverse barometer effect, but for a constant ratio of 0.229 since $\delta_{\mathrm{dte}}=2.277 \times 10^{-3}\left(P_{a}-\right.$ 1013.3). As far as energy is concerned, this leads to a ratio of 0.05 , so that the dry tropospheric effect spectrum would be well below the inverse barometer spectrum.

We believe that our results are only marginally affected by atmospheric effects. However, this is a mean error budget, and local effects cannot be ruled out, particularly for lowenergy areas.

Ionospheric and residual geoid errors must also be considered; although less important, they do contribute to the error budget. Ionospheric correction is not thought to be a major problem, because our study was conducted during a period of relatively low solar activity, where these effects are typically small. Thus it was lower than during the Seasat mission (solar activity was higher in 1978 than in 1987), where it was already not very significant in the error budget [Lorell et al., 1982]. However, this effect might explain a surprising feature of the spectra in strip 4 (Figure $5 \mathrm{c}$ ): they all show a small "hump" at a wavelength of around $30 \mathrm{~km}$. Although we do not have a satisfactory explanation for this feature, it may be related to variations of the subauroral ionospheric trough, which according to Mendillo and Chacko [1977] is found between geomagnetic latitudes of $50^{\circ}$ and $65^{\circ}$ (in the North Atlantic, this corresponds chiefly to latitudes of strip 4).

Residual geoid contributions do not seem to be significant error sources here. Geosat tracks repeat to within $1 \mathrm{~km}$, which according to $F u$ [1983] gives a mean spectral level of the residual geoid considerably lower than that of the oceanic variability.

\subsection{Comparison With Other Similar Calculations and With in Situ Measurements}

Our wave number spectra results are compatible with those obtained by $F_{u}$ [1983] from Seasat data. Fu obtained slopes of $-4.5 \pm 1.5$ between 100 and $250 \mathrm{~km}$ for the energetic areas and -1 between 100 and $1000 \mathrm{~km}$ for low-energy areas. Given the short duration of the Seasat mission (24 days), which did not permit satisfactory observation of the long wavelengths a priori associated with larger time scales, these values are not significantly different from our estimates. Fu and Zlotnicki [1989] compared Geosat and Seasat spectra over two representative regions of low and high energy levels and showed that the slopes observed were the same for wavelengths under $300 \mathrm{~km}$, Seasat providing only part of the signal for longer wavelengths. De Mey and Ménard [1989] have found slopes of between -3 and -4 in the region of POLYMODE $\left(\approx 25^{\circ}-35^{\circ} \mathrm{N}, 75^{\circ}-65^{\circ} \mathrm{W}\right)$ for Seasat and GEOS 3 data, which also compare well with our results.

Autocorrelation functions can be compared (and validated) with past in situ experiments. The altimetric signal is, indeed, directly comparable to the dynamic height measurements (hd) referenced to a no-motion (or known) level. However, our calculation of spatial scales from altimetry takes account of the ocean variability between 60 and 1500 $\mathrm{km}$ over a period of approximately 2 years. This is not true of in situ studies, which are generally limited both spatially to a few hundred kilometers and temporally to a few months.

During the Mid-Ocean Dynamics Experiment (MODE) $\left(28^{\circ} \mathrm{N}, 70^{\circ} \mathrm{W}\right)$ the first zero crossing of the hd/1500-dbar correlation function was at around $120 \mathrm{~km}$ [McWilliams and Owens, 1976]. The agreement with our data is very good, since the first zero crossing of the correlation functions for groups $35\left(70^{\circ}-60^{\circ} \mathrm{W}, 30^{\circ}-40^{\circ} \mathrm{N}\right)$ and $25\left(70^{\circ}-60^{\circ} \mathrm{W}, 20^{\circ}-30^{\circ} \mathrm{N}\right)$ is 115 and $130 \mathrm{~km}$, respectively. Furthermore, transverse geostrophic velocity correlation functions $g(r)(g(r)=$ $\langle v(x) v(x+r)\rangle$, where the geostrophic velocity $v(x)$ is normal to the track and equal to $g / f \partial \operatorname{SLA}(x) / \partial x)$ show first zero crossings of $55 \mathrm{~km}$ and $60 \mathrm{~km}$, respectively, for these two groups (Figure 10). This again compares well with the MODE and POLYMODE results [McWilliams et al., 1986]. Note that these functions were estimated by an inverse Fourier transform of $g^{2} / f^{2}(2 \pi k)^{2} E_{1}(k)$ after a $100-\mathrm{km}$ filtering of SLA. The agreement between our results and those of MODE, despite the differences in samplings, suggests that at longer wavelengths and for longer periods the mesoscale ocean signal in this particular area is very weak. This is consistent with the frequency wave number spectra generally assumed for mesoscale notions [e.g., Wumsch, 1981].

P. Y. Le Traon and M. Ollitrault (Description of an eddy west of the Mid Atlantic Ridge, submitted to Journal of Marine Research, 1990) compared the Geosat results with those obtained during the Tourbillon experiment [Le Groupe Tourbillon, 1983] and showed that the observed differences on the spatial scales can be explained by the different forms of sampling. For Tourbillon the first zero crossing of the $\mathrm{hd} / 3000$-dbar correlation function was found at around $70 \mathrm{~km}$ [Arhan and Colin de Verdière, 1985] while the equivalent Geosat value was $95 \mathrm{~km}$. By filtering out scales greater than $400 \mathrm{~km}$, which were probably not resolved during Tourbillon given the size of the array $(200 \mathrm{~km})$ and the short duration of 

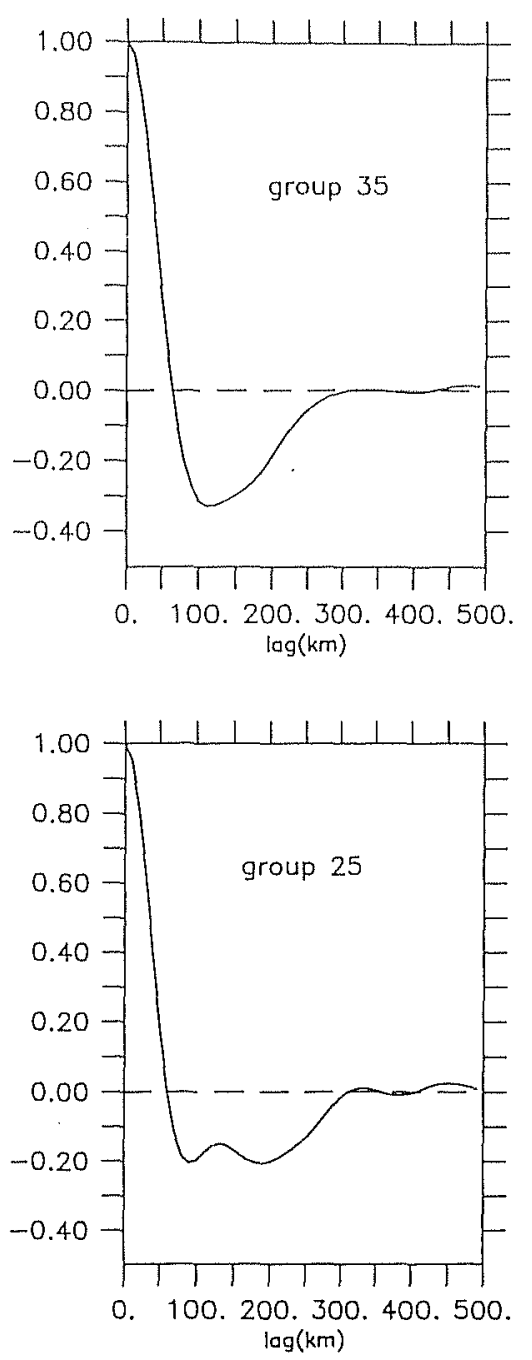

Fig. 10. Transverse geostrophic velocity autocorrelation functions for groups 25 and 35.

the experiment ( 2 months), the two sets of results became similar.

These comparisons therefore show that the spatial scales obtained with Geosat are compatible with in situ measurements, thus validating some of our results.

As noted in section 4, characteristic scales between strip 2 and strip 3 can vary negatively with the internal radii given by Emery et al. [1984]. This result is interesting and can be compared with the ratio $R=$ EKE/EPE in this area. Thus for groups 25 and 35 the mean EPE values obtained from Dantzler [1977] are around $100 \mathrm{~cm}^{2} \mathrm{~s}^{-2}$ and $1300 \mathrm{~cm}^{2} \mathrm{~s}^{-2}$, respectively, for corresponding mean EKE values of 160 $\mathrm{cm}^{2} \mathrm{~s}^{-2}$ and $900 \mathrm{~cm}^{2} \mathrm{~s}^{-2}$ (drifters, Plate 2, bottom) or 320 $\mathrm{cm}^{2} \mathrm{~s}^{-2}$ and $1200 \mathrm{~cm}^{2} \mathrm{~s}^{-2}$ (Geosat, Plate 2, top). The factor of 2 or more for a comparison of $R$ between these two groups could explain the smaller scales (with regard to internal radii) observed for group 25. Similarly, the spatial scales obtained for strip 5 are larger than simple proportionality with respect to the internal radii would imply. The first results of the Athena experiment $\left(53^{\circ} \mathrm{N}, 25^{\circ} \mathrm{W}\right)$ seem to confirm our observations [Boissier et al., 1988].

\subsection{Comparison With Theory and Models}

The wave number spectra of energetic groups at the western end of the basin (groups 35, 34, 33, and 43) have slopes of around -4 from 100 to $300-400 \mathrm{~km}$, according to latitude. These slopes are close to the values given by the theory of quasi-geostrophic turbulence [Charney, 1971]. Indeed, where the movements are sufficiently energetic for dispersion of Rossby waves to be ignored, the theory predicts kinetic energy spectrum slopes of -3 for scales smaller than twice the first Rossby internal radius. In isotropic conditions these kinetic energy slopes of -3 correspond to slopes of -5 for altimetric heights $[F l l, 1983]$. In these western areas the most likely explanation of the generation of eddy energy is the instability (baroclinic or barotropic) of the mean currents. Recent simulations of quasi-geostrophic turbulence forced by the baroclinic instability of a mean shear [Hua and Haidvogel, 1986] confirmed Charney's hypotheses. They have also shown that spectral peaks occur at scales of roughly twice the first internal radius (exactly $7 / 4$ in their simulations), slightly lower than the barotropic $\beta$ arrest scale $k_{\beta}$ [Rhines, 1977], i.e., the scale at which the dispersion of Rossby waves begins to dominate the ocean signal. Although our results give weaker slopes, their shapes are close to those obtained by numerical simulation, in terms of both of the spectral peak and of the behavior beyond the break where the energy level decreases very fast. Thus Figure $6 b$, which gives the kinetic energy spectrum for group 35 calculated from (3), has a peak between 300 and $400 \mathrm{~km}$, corresponding to approximately twice the wavelength for the mean internal radius for the group $(2 \pi \times 32 \mathrm{~km}$ [Emery et al., 1984]). This can also be verified for groups 33 and 34, whose SLA spectra have a peak between 300 and $400 \mathrm{~km}$ (it is ealsy to show that kinetic energy and SLA spectra have the same spectral peak). However, group 43 has a peak at around 300 $\mathrm{km}$, a larger wavelength relative to the mean internal radius there $(13 \mathrm{~km})$. This could suggest that other dynamical processes such as wind forcing or bathymetry are active there.

In lower-energy regions, one of the possible eddygenerating mechanisms is forcing by fluctuating winds [Frankignoul and Müller, 1979; Müller and Frankignoul, 1981]. These authors used a linear model to study the quasi-geostrophic response of the ocean to wind forcing and found energy levels comparable with in situ observations. They obtained wave number spectra, expressed in relation to the stream function, with slopes of -3 for the baroclinic part, while the barotropic part formed by resonant Rossby waves has a $k^{-4}$ spectrum [see Müller and Frankignoul, 1981, Figure 5]. However, these oceanic models are not very realistic, since they do not accurately reproduce the temporal scales and the vertical structure of the currents. If nonlinearities are considered, the ocean signal is different; the time scales are better reconstructed, but the vertical structure is not sufficiently intensified at the surface to agree with in situ data such of those of Tourbillon [Tréguier and Hua , 1987]. However, if small-scale topography is included in these wind forcing simulations, the structures are far more realistic [Tréguier and Hua, 1988]. However realistic these different wind forcing models may be, they all point to a higher energy level at larger scales than in the case of forcing due to instability of a mean current, since the wind forcing and thus the energy input are mostly at larger scales. Our 
results show this behavior for groups in which the spectra remain red at longer wavelengths. It is indeed in such regions (e.g., groups 31,40 , and 41) that the wind effect has been put forward (the Tourbillon site is in the group 40 area). Altimetric spectral peaks are found at larger wavelengths than those predicted by the Hua and Haidvogel [1986] model, and this can also reflect a wind forcing effect. The Treguier and Hua [1987] simulations have shown, indeed, that the parameter which most influences the oceanic response to wind forcing is the ratio of the largest forced wavelength to the wavelength of the first baroclinic Rossby radius. Qualitatively, our results seem to agree with the Tréguier and Hua [1987] model. However, our spectral slopes are around -3 in these low-energy areas, which is weaker than in these nonlinear simulations.

The well-defined "intermediate regime" for certain groups east of the Mid-Atlantic Ridge (see section 3) should perhaps be related to small-scale topography. Since the ocean floor is particularly rough east of the ridge, small-scale topographic effects should be more significant there. Tréguier and Hua [1988] have shown that small-scale topography in wind forcing simulations causes a transfer of energy to small horizontal scales. It considerably reduces the mean scale of the barotropic mode and becomes the main source of energy for the second baroclinic mode. Consequently, the topography induces an energy surplus for scales smaller than the first internal radius.

The spectra of groups 21,22 , and 30 have smaller slopes and do not show a break in the slope. As they are associated with very low energy levels, the dynamics are probably in a more linear regime in opposition to other spectra where nonlinear interactions seem to dominate the dynamics for scales smaller than the spectral peaks.

Our results thus point to certain characteristics which are well represented by the models, at least qualitatively. However, the altimetric height spectra are whiter than those derived through modeling. One possible effect is the infuence of the mesoscale variability of the mixed layer induced by atmospheric forcing. It may indeed be possible to ascribe part of the surface mesoscale variability to atmospheric forcing, the rest being induced by the underlying quasigeostrophic flow. The relative importance of these two factors is poorly documented, and studies are under way to better understand it [e.g., Klein and Hua, 1988]. Thus, according to the importance of atmospheric forcing, the altimetric spectra may or nay not be directly comparable with the results of the quasi-geostrophic simulations. The sea surface variability of the mixed layer is associated with small scales and fronts which can cause significant departures from geostrophy. This ageostrophic part of the signal has a wave number spectrum whiter than the geostrophic part (B. L. Hua, personal communication, 1989). The relative influence of this effect will increase for shorter wavelengths and could explain the weaker slopes found with altimetry.

\section{Conclusions}

For the first time a systematic study of wave number spectra and a characterization of spatial scales has been done on the scale of an ocean basin. Sea surface height variability and eddy kinetic energy have been mapped from 2 years of Geosat data. It has also been shown that the spatial and temporal sampling of Geosat is well suited to mesoscale studies. The comparison of eddy kinetic energy obtained with Geosat data agrees quite well with that obtained with surface drifters. Furthermore, the ratio of sea surface height variability to geostrophic velocity variability has revealed interesting features of the spatial scales of mesoscale motion which have been found to agree with the wave number and autocorrelation calculations.

Wave number spectra have been characterized by three different regimes occurring at different wavelength bands: an "intermediate regime" between $50 \mathrm{~km}$ and $100-200 \mathrm{~km}$, sometimes nonexistent, with slopes of around - l; a band of wavelengths with red spectra and well-defined slopes, typically -4 at the western part of the basin and between -2 and -3 in the other areas; and then a break in the slope occurring after a peak wavelength. All these features show significant differences as a function of latitude and longitude. Spatial scales, as calculated from autocorrelation functions, typically decrease from west to east and south to north. Simple proportionality with respect to the first internal Rossby radii does not apply everywhere. Although the difference sources of error on altimetric measurement cannot be ruled out, particularly for low energy levels, the results are thought to be globally robust.

The comparison of spatial scales works well with MODE in situ data. Tourbillon in situ data give smaller spatial scales, but this can be related to the different forms of sampling of the oceanic signal. General features of wave number spectra are consistent with an eddy forcing by instability of mean currents in the energetic regions and by fluctuating winds in the low-energy regions. There are also some indications of small-scale topographic effects east of the Mid-Atlantic Ridge. Spectral slopes are, however, weaker than those of quasi-geostrophy theory and models, possibly due to nongeostrophic effects. As models become more realistic in terms of resolution, bathymetry, and wind forcing, their mesoscale features should be compared with such data as a test for the energy input and for dissipation.

Acknowledgments. We thank L. Hua, P. De Mey, and J. F. Minster for their comments and advice. Geosat data were processed at GRGS/CNES (Groupe de Recherche en Géodésie Spatiale). This study was supported by a SHOM/GERDSM/CLS Argos contract, A 894864800 . One of our group (P.Y.L.T.) was also supported by a CNRS/DRET contribution, 509291, and a CLS Argos CIFRE grant.

\section{REFERENCES}

Arhan, M., and A. Colin de Verdière, Dynamics of eddy motions in the eastern North Atlantic, J. P/tys. Oceanogr., 15, 153-170, 1985.

Bisagni, J. J., Wet tropospheric range corrections for satellite altimeter-derived dynamic tapographies in the western North Allantic, J. Geophys. Res., 94(C3), 3247-3254, 1989.

Boissier, C., and Le Groupe Athena, Athena 88, une campagne d'océanographie moyenne échelle dans l'Atlantique Nord-Est, mesures et premiers résultats, paper presented at Atelier de Modélisation de l'Atmosphère, Interactions Océan-Atmosphère, Natl. Cent. for Meteorol. Res., Toulouse, France, Nov, 15-16, 1988.

Bretherton, F. P., R. E. Davis, and C. B. Fandry, A technique for objective analysis design of oceanographic experiments applied to Mode 73, Deep Sea Res., 23, 559-582, 1976.

Charney, J. G., Geostrophic turbulence, J. Atmos. Sci., 28, $1087-$ 1095,1971

Cheney, R. E., B. C. Douglas, R. W. Agreen, L. Miller, D. L. Porter, and N. S. Doyle, Geosal altimeter geophysical data record 
user handbook, Natl. Ocean Serv., Natl. Oceanic and Atmos. Admin., Rockville, Md., 1987.

Daniault, N., and Y. Ménard, Eddy kinetic energy distribution in the Southern Ocean from altimetry and FGGE drifting buoys, $I$. Geophys. Res., 90(C6), 11,877-11,889, 1985.

Dantzler, H. L., Potential energy maxima in the tropical and subtropical North Atlantic, J. Phys. Oceanogr., 7, 512-519, 1977.

De Mey, P., and Y. Ménard, Synoptic analysis and dynamical adjustment of GEOS 3 and Seasat altimeter eddy fields in the northwest Atlantic, J. Geophys. Res., 94(C5), 6221-6230, 1989.

Emery, W. J., W. G. Lee, and L. Magaard, Geographic and seasonal distributions of Brunt Väisälä frequency and Rossby radii in the North Pacific and North Atlantic, J. Phys. Oceanogr., 14, 294-317, 1984.

Frankignoul, C., and P. Müller, Quasi-geostrophic response of an infinite $\beta$-plane ocean to stochastic forcing by the atmosphere, $J$. Phys. Oceanogr., 9, 104-127, 1979.

Fu, L. L., On the wave number spectrum of oceanic mesoscale variability observed by the Seasat altimeter, J. Geophys. Res., $88(\mathrm{C} 7), 4331-4341,1983$.

Fu, L. L., and V. Zlotnicki, Observing oceanic mesoscale eddies from Geosat altimetry: Preliminary results, Geophys. Res. Lett., I6, 457-460, 1989.

Hamming, R. W., Digital Filters, Signal Process. Ser., edited by A. V. Oppenheim, Prentice-Hall, Englewood Cliffs, N. J., 1977.

Hua, B. L., and D. B. Haidvogel, Numerical simulations of the vertical structure of quasi-geostrophic turbulence, J. Atmos. Sci., 43, 2923-2936, 1986.

Jourdan, D., C. Boissier, A. Braun, and J. F. Minster, Influence of wet tropospheric correction on mesoscale dynamic topography as derived from satellite altimetry, J. Geophys. Res., 95, 17,993$18,004,1990$.

Klein, P., and B. L. Hua, Mesoscale heterogeneity of the wind driven mixed layer: Influence of a quasi-geostrophic flow, $J . M a r$. Res., 46, 495-525, 1988.

Le Groupe Tourbillon, The Tourbillon experiment: A study of a mesoscale eddy in the eastern North Atlantic, Deep Sea Res., Part A, 30(5), 475-511, 1983.

Le Traon, P. Y., Contribution of Argos-tracked drifters to the study of ocean circulation: Comparative study and combination with altinetric, hydrographic and sub-surface float data, thèse de doctorat, Univ. Paul Sabatier, Toulouse, France, 1990.

Lorell, J., E. Colquitt, and R. J. Anderle, Ionospheric correction for Seasat altimeter height measurement, J. Geophys. Res., 87(C5), 3207-3212, 1982.

McWilliams, J. C., and W. B. Owens, Estimation of spatial covari- ances from the Mid-Ocean Dynamics Experiment, Tech. Note 115, 25 pp., Natl. Cent. for Atmos. Res., Boulder, Colo., 1976.

McWilliams, J. C., W. B. Owens, and L. Hua, An objective analysis of POLYMODE Local Dynamics Experiment, I, General formalism and statistical model selection, J. Phys. Oceanogr., 16, $483-504,1986$.

Mendillo, M., and C. C. Chacko, The baselevel ionospheric trough, J. Geoplys. Res., 82, 5129-5138, 1977.

Mercier, H., and A. Colin de Verdière, Space and time scales of mesoscale motions in the eastern North Atlantic, J. Phys. Oceanogr., 15(2), 171-183, 1985

Müller, P., and C. Frankignoul, Direct atmospheric forcing of geostrophic eddies, J. Phys. Oceanogr., 11, 287-308, 1981.

Pedlosky, J., Geophysical Fluid Dynamics, 624 pp., SpringerVerlag, New York, 1979.

Rhines, P. B., The dynamics of unsteady currents, in The Sea, vol. 6, Marine Modelling, edited by E. D. Goldberg, I. N. McCane, J. J. O'Brien, and J. H. Steele, pp. 189-318, John Wiley, New York, 1977.

Richardson, P. L., Eddy kinetic energy in the North Atlantic Ocean from surface drifters, J. Geophys. Res., 88(C7), 4355-4367, 1983.

Richman, J. G., C. Wunsch, and N. G. Hogg, Space and time scales of mesoscale motion in the western North Atlantic, Rev. Geophys., 15(4), 385-420, 1977.

Tennekes, H., and J. L. Lumley, A First Course in Turbulence, 300 pp., MIT Press, Cambridge, Mass., 1972.

Tréguier, A. M., and B. L. Hua, Oceanic quasi-geostrophic turbulence forced by stochastic wind fluctuations, J. Phys. Oceanogr., 17. 397-411, 1987.

Tréguier, A. M., and B. L. Hua, Influence of bottom topography on stratified quasi-geostrophic turbulence in the ocean, Geophy's. Astrophys. Fluid Dyn., 43, 265-305, 1988.

Wunsch, C., Low frequency variability in the sea, in Evolution of Physical Oceanography, edited by B. A. Warren and C. Wunsch, pp. 342-374, MIT Press, Cambridge, Mass., 1981.

Zlotnicki, V., L. L. Fu, and W. Patzert, Seasonal variability in global sea level observed with Geosat altimetry, $J$. Geophys. Res., 94(C12), 17,959-17,969, 1989.

C. Boissier, SHOM, CNES/GRGS, 18 Avenue Edouard Belin, 31055 Toulouse, France.

P. Y. Le Traon and M. C. Rouquet, CLS Argos, 18 Avenue Edouard Belin, 31055 Toulouse, France.

(Received January 5, 1990; revised June 11, 1990;

accepted June 11, 1990.) 